\title{
Browning of human adipocytes requires KLF11 and reprogramming of PPAR $\gamma$ superenhancers
}

\author{
Anne Loft, ${ }^{1}$ Isabel Forss, ${ }^{1,8}$ Majken Storm Siersbæk, ${ }^{1,8}$ Søren Fisker Schmidt, ${ }^{1}$ Ann-Sofie Bøgh Larsen, ${ }^{1}$ \\ Jesper Grud Skat Madsen, ${ }^{1,2}$ Didier F. Pisani, ${ }^{3,4,5}$ Ronni Nielsen, ${ }^{1}$ Mads Malik Aagaard, ${ }^{1}$ \\ Angela Mathison, ${ }^{6}$ Matt J. Neville, ${ }^{7}$ Raul Urrutia, ${ }^{6}$ Fredrik Karpe, ${ }^{7}$ Ez-Zoubir Amri, ${ }^{3,4,5}$ \\ and Susanne Mandrup ${ }^{1}$ \\ ${ }^{1}$ Department of Biochemistry and Molecular Biology, University of Southern Denmark, DK-5230 Odense M, Denmark; ${ }^{2}$ The \\ Novo Nordisk Foundation Center for Basic Metabolic Research, University of Copenhagen, DK-2200 Copenhagen, Denmark; \\ ${ }^{3}$ UMR 7277, Centre National de la Recherche Scientifique, ${ }^{4}$ U1091, Institut National de la Santé et de la Recherche Médicale, \\ ${ }^{5}$ Institute of Biology Valrose, University Nice Sophia Antipolis, 06100 Nice, France; ${ }^{6}$ Laboratory of Epigenetics and Chromatin \\ Dynamics, Mayo Clinic, Rochester, Minnesota 55905, USA; ${ }^{7}$ National Institute for Health Research, Oxford Biomedical \\ Research Centre, OX3 7LE Oxford, United Kingdom
}

\begin{abstract}
Long-term exposure to peroxisome proliferator-activated receptor $\gamma(\operatorname{PPAR} \gamma)$ agonists such as rosiglitazone induces browning of rodent and human adipocytes; however, the transcriptional mechanisms governing this phenotypic switch in adipocytes are largely unknown. Here we show that rosiglitazone-induced browning of human adipocytes activates a comprehensive gene program that leads to increased mitochondrial oxidative capacity. Once induced, this gene program and oxidative capacity are maintained independently of rosiglitazone, suggesting that additional browning factors are activated. Browning triggers reprogramming of PPAR $\gamma$ binding, leading to the formation of PPAR $\gamma$ "superenhancers" that are selective for brown-in-white (brite) adipocytes. These are highly associated with key brite-selective genes. Based on such an association, we identified an evolutionarily conserved metabolic regulator, Kruppel-like factor 11 (KLF11), as a novel browning transcription factor in human adipocytes that is required for rosiglitazone-induced browning, including the increase in mitochondrial oxidative capacity. KLF11 is directly induced by PPAR $\gamma$ and appears to cooperate with PPAR $\gamma$ in a feed-forward manner to activate and maintain the brite-selective gene program.
\end{abstract}

[Keywords: browning of human adipocytes; KLF11; PPAR $\gamma$; superenhancer; genomic reprogramming; rosiglitazone] Supplemental material is available for this article.

Received August 12, 2014; revised version accepted November 19, 2014.

Obesity has reached pandemic proportions and poses a tremendous threat to human health. Current strategies for therapy aim at restoring the obesity-causing energy imbalance in humans by either decreasing energy uptake or increasing energy expenditure. In this regard, promising targets for treatment of human obesity are brown and "beige/brite (brown in white)" adipose tissues (Harms and Seale 2013), which have been shown to be metabolically significant tissues in both rodents and adult humans (Kopecky et al. 1995; Guerra et al. 1998; Feldmann et al. 2009; Seale et al. 2011; Ouellet et al. 2012; Yoneshiro et al. 2013). The expression of uncoupling protein 1 (UCP1) in residing adipocytes allows uncoupling of mitochondria and thereby conversion of fatty acids and glucose into heat.

\footnotetext{
${ }^{8}$ These authors contributed equally to this work.

Corresponding author: s.mandrup@bmb.sdu.dk

Article published online ahead of print. Article and publication date are online at http://www.genesdev.org/cgi/doi/10.1101/gad.250829.114.
}

Traditionally, UCP1-positive adipocytes in rodents have been distinguished into classical brown adipocytes from brown adipose tissue (BAT) and brite (Petrovic et al. 2010)/beige (Ishibashi and Seale 2010) (hereafter termed brite) adipocytes from white adipose tissue (WAT) (Harms and Seale 2013). Recently, several studies demonstrated that human adults have separate depots of brown(-like) adipocytes interspersed among white adipocytes in the supraclavicular, para-aortic, and suprarenal fat depots (Cypess et al. 2009; van Marken Lichtenbelt et al. 2009; Virtanen et al. 2009). It is currently unclear whether these human brown(-like) adipocytes more resemble the inducible brite

(C) 2015 Loft et al. This article is distributed exclusively by Cold Spring Harbor Laboratory Press for the first six months after the full-issue publication date (see http://genesdev.cshlp.org/site/misc/terms.xhtml). After six months, it is available under a Creative Commons License (Attribution-NonCommercial 4.0 International), as described at http:// creativecommons.org/licenses/by-nc/4.0/. 
adipocytes found in the WAT of mice rather than the classical brown adipocytes from BAT (Sharp et al. 2012; Wu et al. 2012; Cypess et al. 2013; Lidell et al. 2013). Nevertheless, there is a growing clinical interest in understanding how brite adipocytes develop, especially since the emergence of brite adipocytes in WAT is associated with protection against obesity and metabolic dysfunctions in several rodent models (Seale et al. 2011; Cohen et al. 2014).

The appearance of brite adipocytes can be induced by several different thermogenic stimuli, including cold and $\beta$-adrenergic stimulation (Cousin et al. 1992; Himms-Hagen et al. 1994). In addition, long-term exposure to synthetic ligands of peroxisome proliferator-activated receptor $\gamma$ $(\operatorname{PPAR} \gamma)$, a key activator of both white and brown adipocyte differentiation (Lefterova et al. 2014), has been shown to promote the formation of functional brite adipocytes in cultures of rodent white adipocytes and in WAT (Fukui et al. 2000; Wilson-Fritch et al. 2004; Petrovic et al. 2010). Interestingly, studies using human preadipocytes, including human multipotent adiposederived stem (hMADS) cells, indicate that the ability of PPAR $\gamma$ agonists to induce functional brite cells is conserved in humans (Digby et al. 1998; Elabd et al. 2009). Mechanistically, it has been suggested that PPAR $\gamma$ ligands induce brown/brite-selective genes by directly activating $\operatorname{PPAR} \gamma$ at nearby regulatory regions (Sears et al. 1996). However, browning is not immediately induced (Petrovic et al. 2010; Haakonsson et al. 2013), indicating that activation and stabilization of the brite adipocyte gene program by rosiglitazone requires activation of additional indirect effectors that may help reprogram the chromatin template. Candidates for such rosiglitazone-induced effectors have been identified in rodents and include the cofactors PGC- $1 \alpha$ (Hondares et al. 2006) and PRDM16 (Ohno et al. 2012). At present, however, these rosiglitazone-induced effectors remain elusive. Furthermore, little is known about the molecular mechanisms underlying browning of human adipocytes, and genome-wide insight into the transcriptional reprogramming of the genome and the transcriptional networks involved is completely lacking.

In this study, we characterized for the first time the transcriptional processes underlying browning of human adipocytes using a genome-wide approach. We show that this is associated with reprogramming of PPAR $\gamma$ binding to form brite-selective PPAR $\gamma$ superenhancers that appear to play a key role in activation of brite-selective genes. We identify the Kruppel-like factor 11 (KLF11) gene based on its association with a brite-selective PPAR $\gamma$ superenhancer and show that KLF11 is a novel browning factor directly induced by rosiglitazone and required for the activation of brite-selective genes by rosiglitazone.

\section{Results}

Browning of human adipocytes stimulates a comprehensive stable gene program linked to mitochondrial oxidative capacity

To explore the transcriptional mechanisms underlying the browning process of human adipocytes, we exposed mature white hMADS adipocytes to the PPAR $\gamma$ ligand, rosiglitazone, for $3 \mathrm{~d}$ (i.e., days $13-16$ of differentiation) (Fig. 1A). As previously shown, rosiglitazone induces the expression of well-established brown/brite adipocyte markers (Elabd et al. 2009; Pisani et al. 2011) such as UCP1, CIDEA, ELOVL3, and DIO2, whereas expression of the common adipocyte markers PLIN1/2, SCD, and FASN as well as the degree of fat synthesis and lipid accumulation are comparable in white and brite adipocytes (Fig. 1B-D; Supplemental Fig. S1A-C). Interestingly, once induced, the expression of brite-selective marker genes is maintained from day 16 to day 19 and further until day 23 independently of continued rosiglitazone administration (Fig. 1C,D), indicating that a stable brite adipocyte gene program has been switched on. Establishment of a full brite phenotype requires long-term exposure to rosiglitazone, since a short 2 -h pulse of rosiglitazone in mature hMADS adipocytes at day 13 is insufficient for full activation of $U C P 1$ transcription (Supplemental Fig. S1D), suggesting that the induction of additional factors are needed to effectively activate a brite gene program in hMADS adipocytes.

To examine the global transcriptional changes associated with browning of white adipocytes, we performed RNA sequencing (RNA-seq) in hMADS preadipocytes as well as in mature white and brite hMADS adipocytes deprived of rosiglitazone. Principal component analysis based on gene expression profiles showed that preadipocytes and white and brite hMADS adipocytes separate into three clusters corresponding to distinct cell types (Supplemental Fig. S2A). Comparison of white and brite adipocytes identified a total of 2829 differentially expressed genes (false discovery rate $[\mathrm{FDR}]<0.05$ ), of which 1691 are brite-selective and 1138 are white-selective (Fig. 1E; Supplemental Fig. S2B). Notably, several known white and brown/brite marker genes are differentially expressed between white and brite hMADS adipocytes (Fig. 1F). The gene programs that are selective for brite adipocytes are associated with increased mitochondrial function and energy consumption (Supplemental Table S1; Supplemental Fig. S2C). Importantly, this leads to a significant increase in basal, maximal, and uncoupled respiration in brite compared with white adipocytes, which is maintained in rosiglitazone-deprived brite adipocytes at day 19 (Fig. 1G). In contrast, genes selectively expressed in white hMADS adipocytes belong to pathways associated with amino acid metabolism (Supplemental Table S1). Taken together, these results demonstrate that distinct "stable" gene programs are active in white and brite hMADS adipocytes and that the brite-selective gene program is associated with functional properties of the brite adipocytes.

\section{Cell type-selective PPAR $\gamma$ binding correlates with active chromatin signatures and cell type-selective gene expression}

To determine the degree of reprogramming of the chromatin template and identify putative active chromatin regions (Crawford et al. 2006), we generated genome-wide DNase I-hypersensitive (DHS) site profiles in white and 
A

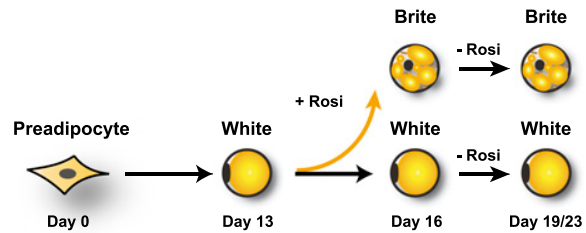

B
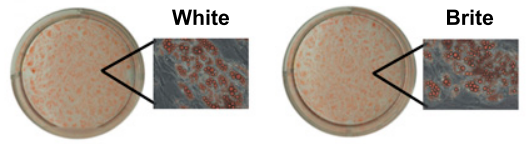

D
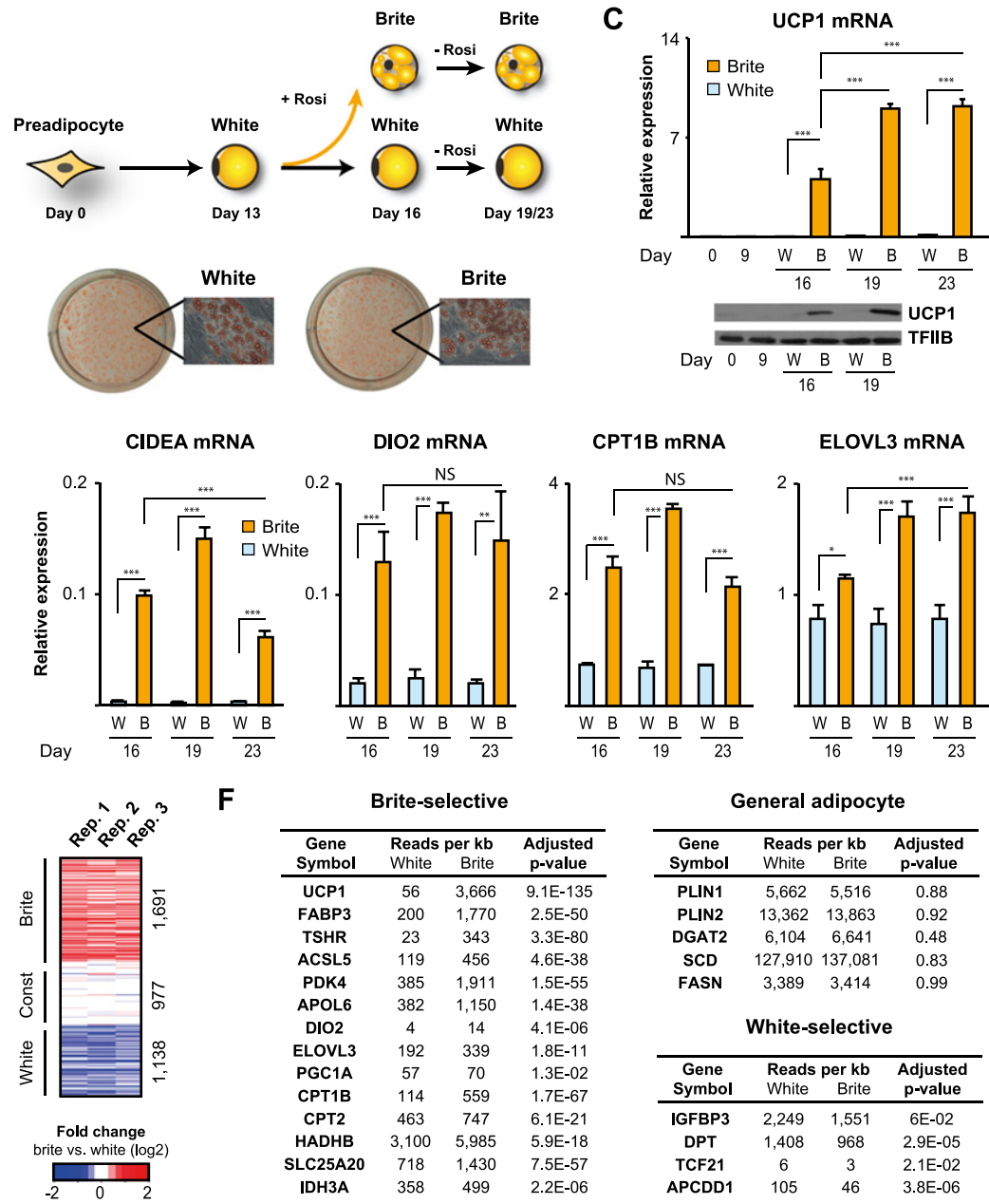

F

\begin{tabular}{cccc}
\multicolumn{4}{c}{ Brite-selective } \\
\hline $\begin{array}{c}\text { Gene } \\
\text { Symbol }\end{array}$ & \multicolumn{2}{c}{$\begin{array}{c}\text { Reads per kb } \\
\text { White }\end{array}$} & $\begin{array}{c}\text { Brite } \\
\text { Adjusted } \\
\text { p-value }\end{array}$ \\
\hline UCP1 & 56 & 3,666 & $9.1 \mathrm{E}-135$ \\
FABP3 & 200 & 1,770 & $2.5 \mathrm{E}-50$ \\
TSHR & 23 & 343 & $3.3 \mathrm{E}-80$ \\
ACSL5 & 119 & 456 & $4.6 \mathrm{E}-38$ \\
PDK4 & 385 & 1,911 & $1.5 \mathrm{E}-55$ \\
APOL6 & 382 & 1,150 & $1.4 \mathrm{E}-38$ \\
DIO2 & 4 & 14 & $4.1 \mathrm{E}-06$ \\
ELOVL3 & 192 & 339 & $1.8 \mathrm{E}-11$ \\
PGC1A & 57 & 70 & $1.3 \mathrm{E}-02$ \\
CPT1B & 114 & 559 & $1.7 \mathrm{E}-67$ \\
CPT2 & 463 & 747 & $6.1 \mathrm{E}-21$ \\
HADHB & 3,100 & 5,985 & $5.9 \mathrm{E}-18$ \\
SLC25A20 & 718 & 1,430 & $7.5 \mathrm{E}-57$ \\
IDH3A & 358 & 499 & $2.2 \mathrm{E}-06$
\end{tabular}

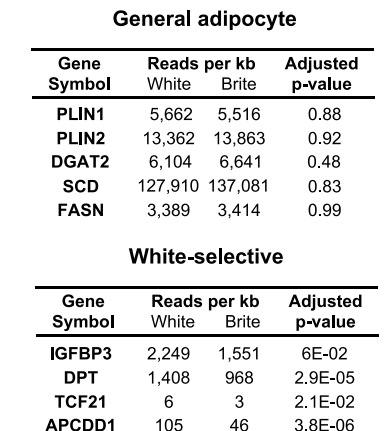

G
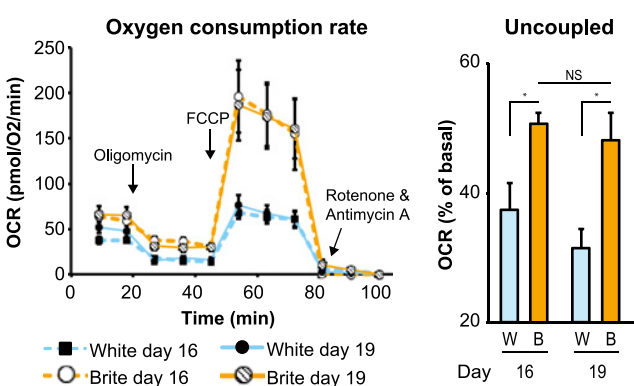
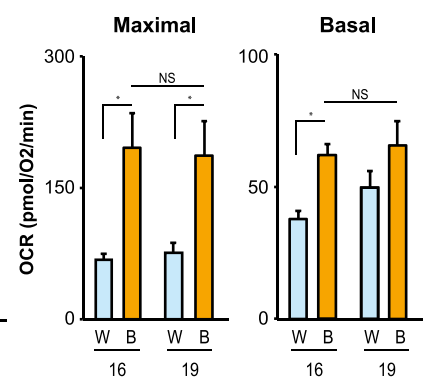

Figure 1. Browning of hMADS adipocytes induces a stable gene program linked to enhanced mitochondrial oxidative capacity. (A) Schematic overview of hMADS differentiation. hMADS cells were induced to differentiate using an adipogenic cocktail. Mature white adipocytes were treated with DMSO to remain white adipocytes or with rosiglitazone (+rosi) to become brite adipocytes. Rosiglitazone was omitted from the differentiation medium from day 16. $(B)$ White and brite hMADS adipocyte cultures were fixed with formaldehyde and stained with oil-red-O. Representatives of phasecontrast micrographs are displayed. $(C, D)$ Expression of UCP1 $(C)$ and brown/brite adipocyte markers $(D)$ in white $(\mathrm{W}$, light blue) and brite (B, orange) hMADS adipocytes at the indicated days. Error bars represent $\operatorname{SD}(n=3) .\left(^{\star \star \star}\right) P<0.001 ;\left(^{\star \star}\right) P<0.005$; $\left({ }^{\star}\right) P<0.05$; (NS) not significant $(P>0.05)$, as indicated. $(E)$ Heat map showing $\log _{2}$ fold change for white-selective (1138 genes) and brite-selective (1691 genes) (FDR $<0.05$ ) genes as well as a group of constitutively expressed genes $(977$ genes with FDR $>0.9$ and $\log _{2}$ fold change $<2.5 \%$ ) from three independent biological replicates in white and brite hMADS adipocytes at day 19. $(F)$ Mean expression values (as normalized exon reads per kilobase) from three RNA-seq data replicates for a subset of previously reported brite- and white-selective genes as well as general adipocyte markers. $(G)$ Oxygen consumption rate (OCR) measured in white (W, light blue) and brite (B, orange) hMADS adipocytes at days 16 and 19. (Left) The arrows indicate time of addition for oligomycin, FCCP, and rotenone/antimycin A. (Right) Uncoupled, maximal, and basal respiration in white and brite hMADS adipocytes. Error bars represent SEM $(n=3) .\left(^{\star}\right) P<$ 0.05 as indicated. brite hMADS adipocytes. Notably, despite considerable changes in gene expression during browning, the DHS profiles overall were very similar in white and brite adipocytes (Supplemental Fig. S3A,B), indicating that the transcriptional changes during browning occur without major changes in the chromatin landscape.

We and others have recently shown the existence of robust fat depot-selective binding of PPAR $\gamma$ linked to depot-specific gene expression in mice (Siersbæk et al. 2012; Rajakumari et al. 2013), indicating that PPAR $\gamma$, in addition to its role as a general activator of adipogenesis in mice (Lefterova et al. 2008; Nielsen et al. 2008) and humans (Mikkelsen et al. 2010; Schmidt et al. 2011; Soccio et al. 2011), plays a prominent role in the induction of genes characteristic of different adipocyte lineages. The fact that browning is induced by the PPAR $\gamma$ ligand rosiglitazone indicates that PPAR $\gamma$ is also a major driver of the genomic reprogramming during browning. To investigate this, we generated PPAR $\gamma$ chromatin immunoprecipitation (ChIP) sequencing (ChIP-seq) profiles in white and brite hMADS adipocytes. From a total of 52,030 PPAR $\gamma$-binding sites, we identified 4439 reprogrammed PPAR $\gamma$-binding sites with differential PPAR $\gamma$-binding intensity (FDR $<0.1$ ) in white and brite adipocytes (2228 white-selective and 2211 briteselective) (Fig. 2A). Furthermore, we defined a group of 2385 constant sites that show comparable PPAR $\gamma$-binding signal in these two cell populations. Notably, levels of PPAR $\gamma$ protein are comparable in brite and white adipocytes 
Loft et al.
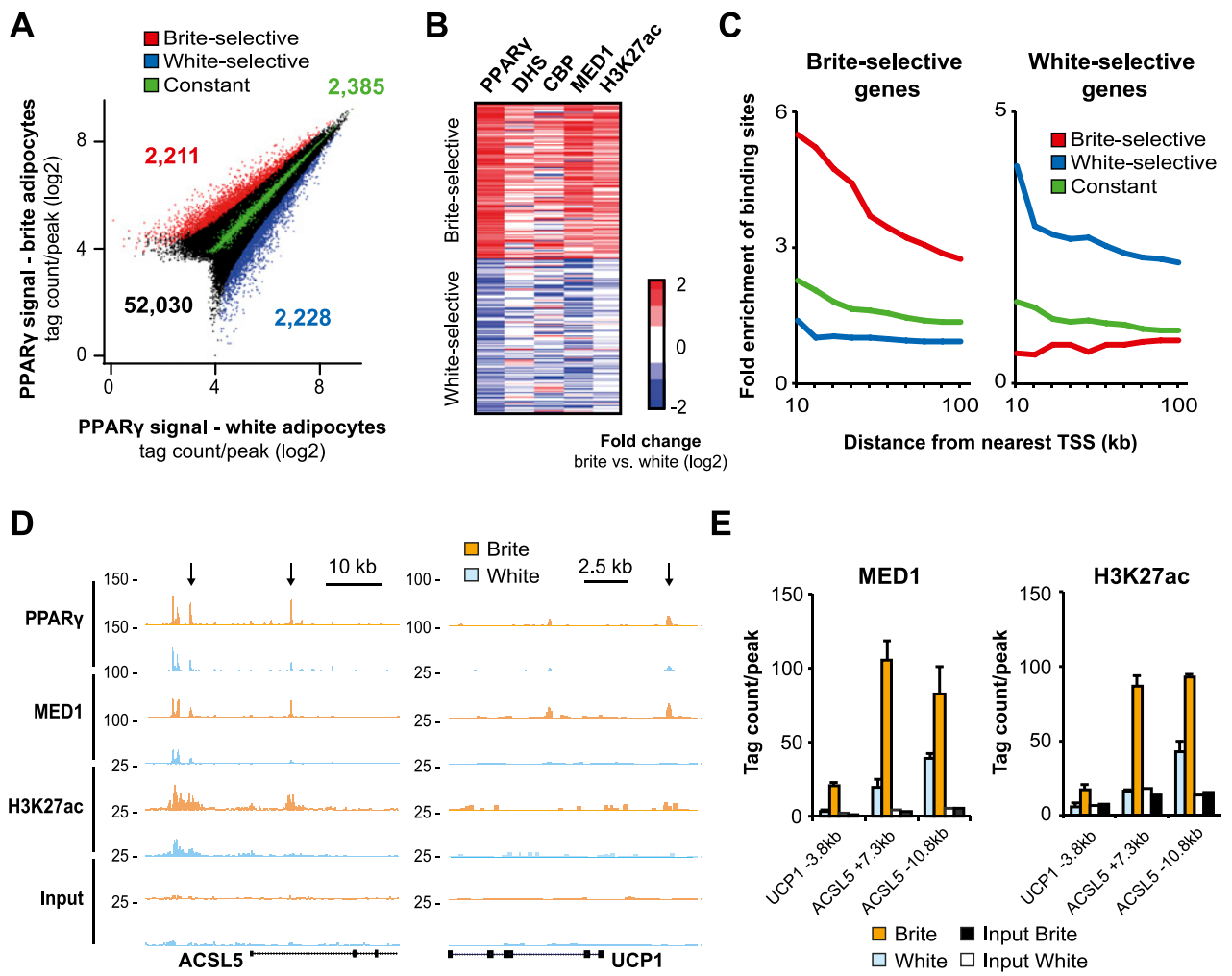

Figure 2. PPAR $\gamma$ binding is reprogrammed during browning of hMADS adipocytes. (A) Scatter plot showing PPAR $\gamma$ signal (as edgeRnormalized tag count in a 400-base-pair [bp] window) in PPAR $\gamma$-binding sites in white and brite hMADS adipocytes at day 19. Reprogrammed (FDR < 0.1) white-selective (blue, 2228 peaks) and brite-selective (red, 2211 peaks) PPAR $\gamma$-binding sites are shown. A group of constant PPAR $\gamma$-binding sites (green, 2385 peaks) was defined as those having a FDR $>0.95$ and a fold change $<2.5 \%$. The remaining PPAR $\gamma$-binding sites are black. (B) Heat map showing the $\log _{2}$ fold change in PPAR $\gamma$, DHS, CBP, MED1, and H3K27ac signal at reprogrammed PPAR $\gamma$-binding sites in brite compared with white hMADS adipocytes. PPAR $\gamma$, DHS, CBP, and MED1 signals were counted in a 400-bp window, and H3K27ac signal was counted in a 2-kb window around the PPAR $\gamma$ peak center. $(C)$ Enrichment of the brite-selective (red), white-selective (blue), and constant (green) PPAR $\gamma$-binding sites in the vicinity of top brite-selective (603 genes) or white-selective (292 genes) genes. Enrichment was determined as the number of binding sites per gene within different distances from the transcription start site (TSS; 10-100 kb) of top regulated genes relative to the number of binding sites per gene of constitutively expressed genes, as defined in Figure 1E. (D) ChIP-seq profiles of PPAR $\gamma$, MED1, H3K27ac, and input control at the ACSL5 and UCP1 loci in white and brite hMADS adipocytes. The arrows indicate brite-selective PPAR $\gamma$-binding sites. (E) Bar plot showing the mean tag count in brite-selective PPAR $\gamma$-binding sites (indicated with arrows in $D$ ) for duplicate MED1 (400-bp window) and H3K27ac (2-kb window) ChIP-seq libraries in white (light blue) and brite (orange) hMADS adipocytes. The input signal in white (white) and brite (black) hMADS adipocytes in the given window is plotted as a control. Error bars represent SEM $(n=2)$.

(Supplemental Fig. S4A). The fact that $<10 \%$ of the total number of PPAR $y$-binding sites is reprogrammed indicates that most of the transcriptional functions of PPAR $\gamma$ are maintained in the brite adipocytes. Nevertheless, reprogrammed PPAR $\gamma$-binding sites are high-intensity sites compared with the group of constant sites and thus are likely to represent key regulatory elements (Supplemental Fig. S4B). De novo motif analysis did not show major differences in motif enrichment between the different groups of sites. The PPAR response element is the top-scoring motif in all three groups, whereas the NF1 half-site is enriched in white-selective and constant PPAR $\gamma$ binding sites, and the C/EBP motif is enriched in briteselective and constant PPAR $\gamma$-binding sites (Supplemental Fig. S4C). To investigate the activity of these reprogrammed PPAR $\gamma$-binding sites, we evaluated the DHS sequencing (DHS-seq) profiles as well as ChIP-seq profiles of the subunit 1 of the Mediator complex (MED1), the coactivator CREB-binding protein $(\mathrm{CBP})$, and the histone mark H3K27ac, all of which are known to be marks of active regulatory regions (Crawford et al. 2006; Heintzman et al. 2009; Creyghton et al. 2010; Kagey et al. 2010; Rada-Iglesias et al. 2011). Interestingly, brite-selective PPAR $\gamma$-binding sites are found in regions that appear to be most active in brite adipocytes (Fig. 2B; Supplemental Fig. S4D). Similarly, white-selective PPAR $\gamma$-binding sites are found in regions with elevated activity in white adipocytes, whereas constant PPAR $\gamma$-binding sites display no major differences in activating chromatin marks between white and brite adipocytes. These results demonstrate that although no major overall changes occur in the chromatin template during browning, the reprogrammed PPAR $\gamma$ binding sites are associated with local remodeling of the chromatin and signatures of increased transcriptional 
activity. The role of PPAR $\gamma$ as a major determinant of enhancer activity is supported by the fact that $\operatorname{PPAR} \gamma$ binding positively correlates with activating enhancer signatures at all identified PPAR $\gamma$-binding sites (Supplemental Fig. S5A). Interestingly, the cell type-selective PPAR $\gamma$-binding events are highly enriched near cell typeselective genes (Fig. 2C), including brite-selective genes such as UCP1 and ACSL5 (Fig. 2D,E; Supplemental Fig. S5B). Thus, these genome-wide analyses extend previous results based on single genes and indicate that PPAR $\gamma$ is a critical direct activator of the brite-selective gene program.

\section{Brite-selective PPAR $\gamma$ superenhancers are highly enriched near brite-selective genes}

It has recently been shown that superenhancers (i.e., clusters of enhancers) constitute particularly powerful regulatory nodes controlling expression of genes defining cell identity (Loven et al. 2013; Whyte et al. 2013). To identify such key regulatory regions in hMADS adipocytes and determine whether they change during browning, we merged all identified PPAR $\gamma$-binding sites in close proximity (within $12.5 \mathrm{~kb}$ from each other) and ranked them according to the intensity of their associated MED1 signal. Using this approach, we identified 1106 PPAR $\gamma$ superenhancers in brite adipocytes that have elevated levels of MED1 signal compared with regular PPAR $\gamma$ binding regions in two independent biological replicates (Fig. 3A). Compared with regular PPAR $\gamma$ enhancers, the constituent PPAR $\gamma$-binding regions within PPAR $\gamma$ superenhancers are enriched in MED1, H3K27ac, DHS, and CBP signal (Fig. 3B; Supplemental Fig. S6A), indicating that the constituent PPAR $\gamma$ enhancers in superenhancers are significantly more active than regular PPAR $\gamma$ enhancers. Furthermore, the PPAR $\gamma$ signal intensity is higher in the PPAR $\gamma$ superenhancer constituents compared with regular PPAR $\gamma$-binding regions, indicating that $\operatorname{PPAR} \gamma$ plays an active role in the formation of superenhancers.

To identify key cell type-selective regulatory regions, we examined PPAR $\gamma$ superenhancers with differential MED1 signal in white and brite adipocytes. From a total of 1212 superenhancers identified in white and/or brite adipocytes, we identified 304 white-selective and 324 brite-selective (FDR $<0.01)$ as well as 148 constant $\operatorname{PPAR} \gamma$ superenhancers (Fig. 3C). Interestingly, brite- and white-selective PPAR $\gamma$-binding sites are highly enriched in brite- and white-selective superenhancers, respectively (Fig. 3D). Furthermore, PPAR $\gamma$-binding intensity is significantly higher at brite-selective sites than nonreprogrammed PPAR $\gamma$ sites within brite-selective superenhancers (Supplemental Fig. S6B). This indicates that superenhancers with cell type-selective activity arise as a consequence of PPAR $\gamma$ reprogramming during the browning process. This is further supported by the fact that within these superenhancers, the increase in MED1 and H3K27ac signal in brite compared with white adipocytes is more pronounced at enhancer constituents where there is briteselective binding of $\operatorname{PPAR} \gamma$ compared with enhancer constituents where PPAR $\gamma$ binding is independent of cell type (Supplemental Fig. S6C).
Annotation of PPAR $y$ superenhancers to the nearest genes showed that cell type-selective PPAR $\gamma$ superenhancers are highly enriched in the vicinity of cell typeselective genes and that the enrichment is much higher than for regular cell type-selective $\operatorname{PPAR} \gamma$ enhancers (Fig. 3E). Notably, brite-selective genes associated with brite-selective superenhancers are induced significantly more during browning and are expressed at much higher levels compared with brite-selective genes that do not have a super-enhancer associated with them (Fig. 3F). Furthermore, brite-selective genes associated with briteselective superenhancers belong to brite-selective metabolic pathways, such as fatty acid degradation and $\beta$-oxidation (Supplemental Fig. S7A). Several of these metabolic genes are also marked by brite-selective PPAR $\gamma$ superenhancers defined by H3K27ac signal (Supplemental Fig. S7B). Examples of prominent brite-selective genes associated with brite-selective superenhancers are PDK4, ACSL5, $C I D E A$, and DIO2, whereas common PPAR $\gamma$ superenhancers are found near general adipocyte genes such as PLIN1/2 and SCD1 (Fig. 3G,H; Supplemental Fig. S7CG). Taken together, these data indicate that brite-selective PPAR $\gamma$ superenhancers are crucial regulatory regions for controlling key brite-selective genes.

Rosiglitazone treatment induces the superenhancerassociated gene KLF11 in human adipocytes and subcutaneous fat of human type 2 diabetic (T2D) patients

Superenhancers have been reported to be associated with genes that define cellular function (Whyte et al. 2013). In line with this, we identified common white and brite PPAR $\gamma$ superenhancers associated with key adipocyte regulatory factors, including C/EBP $\beta$, PPAR $\gamma$, and STAT5A. To search for novel transcriptional mediators of the rosiglitazoneinduced browning of human adipocytes, we examined the genes associated with a brite-selective PPAR $\gamma$ superenhancer (see Supplemental Fig. S7B for examples). Interestingly, we observed a prominent brite-selective PPAR $\gamma$ superenhancer (as determined by both MED1 and H3K27ac ranking) near the gene encoding KLF11 (Fig. 4A; Supplemental Fig. S7B,E). KLF11 (also called MODY7) is a well-known regulator of pancreatic $\beta$-cell function, and human genetic variants have been associated with dysfunctional $\beta$ cells and diabetes (Neve et al. 2005; Bonnefond et al. 2011). In nonadipocyte cell lineages, KLF11 regulates several metabolic gene networks and acts as both an activator and a repressor of transcription (Fernandez-Zapico et al. 2009; Seo et al. 2012; Lomberk et al. 2013). Moreover, it was recently shown that KLF11 can activate UCP1 expression in mouse bone marrow-derived stem cells (Yamamoto et al. 2010), suggesting that KLF11 could be a browning factor. However, whether and how it functions as such in mice are unclear. Furthermore, its role in human adipocytes remains totally unknown.

Consistent with the association of KLF11 with a briteselective PPAR $\gamma$ superenhancer, we found that KLF11 is expressed at higher levels in brite compared with white 

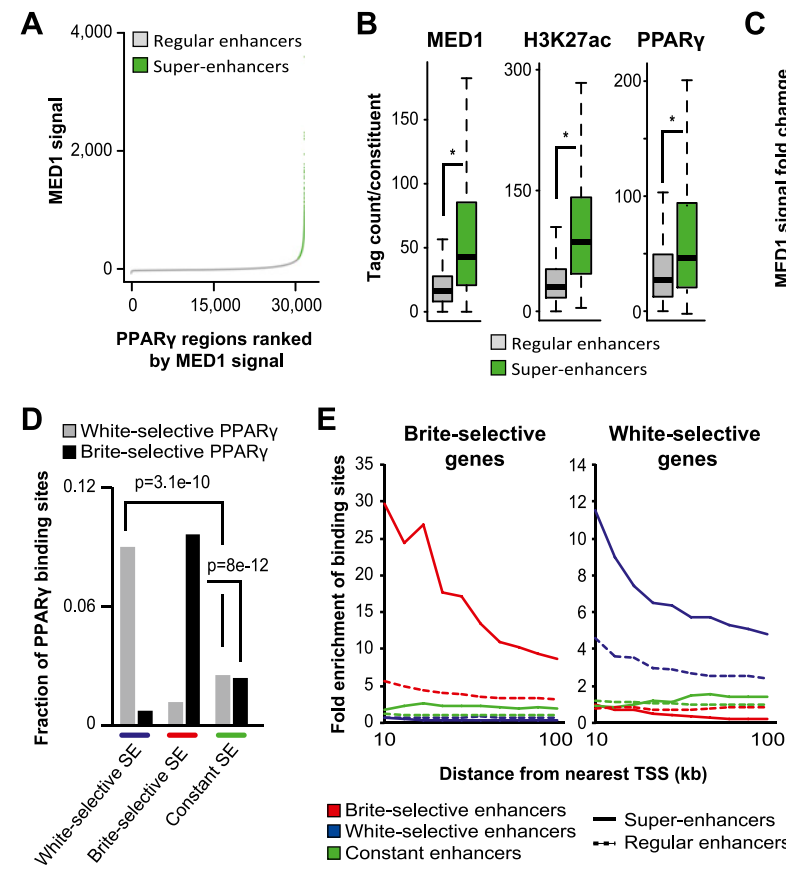
$\square$ White-selective enhancers
$\square$ Constant enhancers
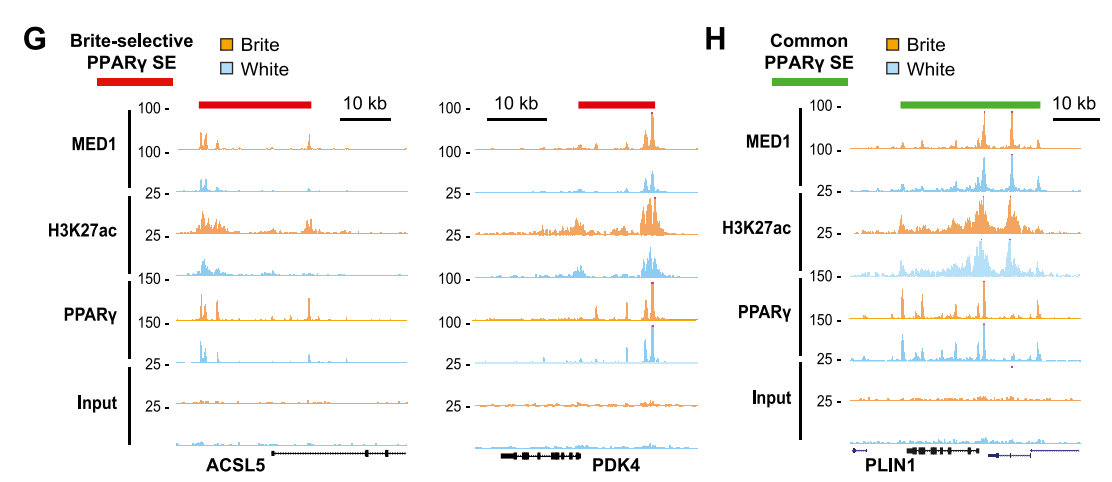

Figure 3. Brite-selective $\operatorname{PPAR} \gamma$ superenhancers are highly enriched near brite-selective genes. (A) All identified PPAR $\gamma$-binding sites $(52,030)$ within $12.5 \mathrm{~kb}$ of each other were merged, resulting in 31,466 regions. These PPAR $\gamma$ regions in brite hMADS adipocytes were ranked according to input-subtracted signal of MED1. Regions with $>200$ reads (minus input signal) per 10 million total reads in both MED1 replicates were defined as superenhancers (green). All other regions were denoted as regular PPAR $\gamma$-binding regions (gray). (B) MED1 and PPAR $\gamma$ (400-bp window) as well as $\mathrm{H} 3 \mathrm{~K} 27 \mathrm{ac}$ (2-kb window) signal (as tag count per peak) in PPAR $\gamma$ constituents in regular PPAR $\gamma$-binding regions (gray, 46,392 peaks) and PPAR $\gamma$ superenhancers (green, 5638 peaks) in brite hMADS adipocytes. $\left(^{\star}\right) P<2.210^{-16}$ as indicated, Wilcoxon rank-sum test. $(C)$ MA plot showing mean MED1 signal (as edgeR-normalized tag count) versus the $\log _{2}$ fold change in MED1 signal for a given PPAR $\gamma$ superenhancer (SE) in brite compared with white hMADS adipocytes. PPAR $\gamma$ superenhancers with significantly (FDR < 0.01) elevated MED1 tag counts in white (blue, 304 regions) and brite (red, 324 regions) hMADS adipocytes are shown. A group of constant PPAR $\gamma$ superenhancers (green, 148 regions) was defined as regions having an FDR $>0.6$, and the rest of the common PPAR $\gamma$ superenhancers are shown in black. $(D)$ Fraction of white-selective (gray) and brite-selective (black) PPAR $\gamma$-binding sites in white-selective (blue), brite-selective (red), and constant (green) PPAR $\gamma$ superenhancers (SE). Significance was determined by Fisher's exact test as indicated. $(E)$ Enrichment of brite-selective (red), white-selective (blue), and constant (green) PPAR $\gamma$ superenhancers (solid line) or regular binding regions (dotted line) near the top brite-selective and white-selective genes. Enrichment was determined as the number of binding sites per gene within different distances from the TSS $(10-100 \mathrm{~kb})$ of the top regulated genes relative to the number of binding sites per gene of constitutively expressed genes, as defined in Figure 1E. $(F) \log _{2}$ fold change in the expression of brite compared with white hMADS adipocytes (left) and normalized exon reads per kilobase in brite hMADS adipocytes (right) for brite-selective genes associated (red) or not (gray) with brite-selective superenhancers. $(G, H)$ ChIP-seq profiles of MED1, H3K27ac, PPAR $\gamma$, and input control at the ACSL5 and PDK4 $(G)$ and PLIN1 $(H)$ loci in white (light blue) and brite (orange) hMADS adipocytes. The red and green lines indicate the positions of brite-selective and common PPAR $\gamma$ superenhancers, respectively.

adipocytes and that this level is maintained at least until day 23 (Fig. 4B; Supplemental Fig. S8A,B). Furthermore, we found compelling evidence that KLF11 is directly activated by PPAR $\gamma$ during browning of human adipocytes. First, we showed that the expression of KLF11 in brite adipocytes is dependent on PPAR $\gamma$ (Fig. 4C; Supplemental Fig. S8C). Second, treatment of mature brite adipocytes with the selective $\operatorname{PPAR} \gamma$ antagonist GW9662 leads to an acute reduction of KLF11 premRNA levels (Supplemental Fig. S8D). Third, KLF11 pre-mRNA levels are significantly induced only $2 \mathrm{~h}$ after rosiglitazone treatment of mature hMADS adipocytes, and this increased transcription is maintained in mature brite adipocytes (Fig. 4D). Collectively, these results indicate that KLF11 is a brite-selective factor directly induced by PPAR $\gamma$ in hMADS adipocytes, most likely as a result of PPAR $\gamma$ binding to clusters of binding sites in the vicinity of the gene.

It has recently been demonstrated that cooling of white and brite murine adipocytes activates a $\beta$-adrenergicindependent thermogenic gene program (Ye et al. 2013). Interestingly, brite (Supplemental Fig. S8E) but not white hMADS adipocytes (data not shown) respond to $4 \mathrm{~h}$ of cooling at $31^{\circ} \mathrm{C}$ by an increase in the expression of UCP1 and a subset of other brite-selective genes, including KLF11. Furthermore, $\beta$-adrenergic stimulation of brite (Supplemental Fig. S8F) but not white hMADS adipocytes (data not shown) leads to a modest increase in UCP1 and KLF11. This demonstrates that although these thermogenic stimuli are insufficient for induction of browning 
A

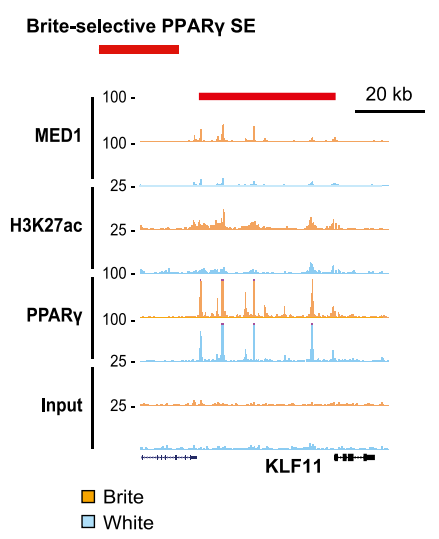

D

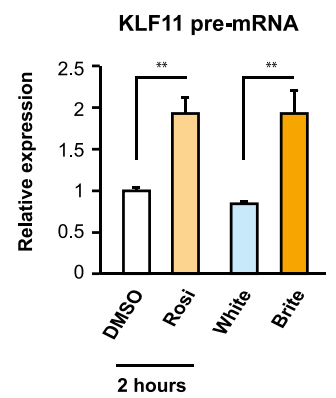

B

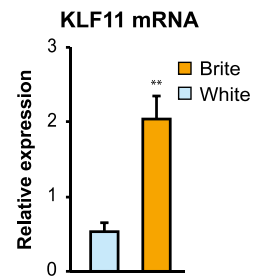

C

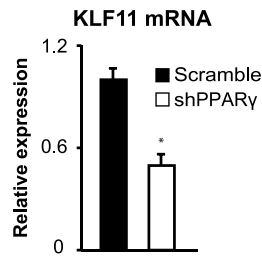

E

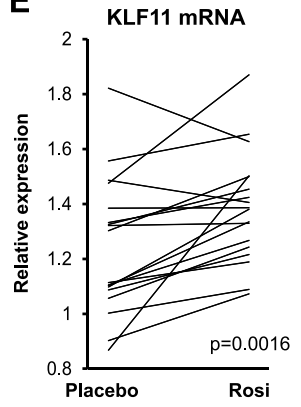

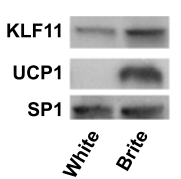

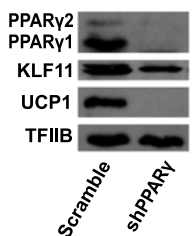

KLF11 mRNA

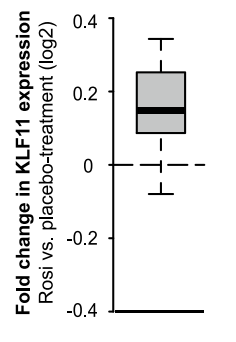

Figure 4. Rosiglitazone treatment induces the superenhancer-associated gene KLF11 in vitro and in vivo. (A) ChIP-seq profiles of MED1, H3K27ac, $\operatorname{PPAR} \gamma$, and input control at the KLF11 locus in white (light blue) and brite (orange) hMADS adipocytes. The red line indicates the position of the brite-selective PPAR $\gamma$ superenhancer. $(B)$ Expression of KLF11 mRNA (left) and KLF11 and UCP1 protein (right) in white (light blue) and brite (orange) hMADS adipocytes at day 19. (C) KLF11 mRNA (left) and protein (right) expression at day 16 of hMADS adipocyte differentiation with or without knockdown of PPAR $\gamma$. hMADS adipocytes were transduced with lentiviral vectors expressing either scramble (black) or PPAR $\gamma$ (white) shRNA at day 10 and subsequently treated with rosiglitazone from day 13 to day 16 to induce browning. (D) KLF11 premRNA levels in hMADS adipocytes at day 13 treated for $2 \mathrm{~h}$ with DMSO (white) or rosiglitazone (light orange) or differentiated to day 19 white (light blue) and brite (orange) adipocytes. In $B-D$, error bars represent $\operatorname{SD}(n=3) .\left(^{\star \star}\right) P<0.005 ;\left(^{\star}\right) P<0.05$. (E) Relative expression (left) and $\log _{2}$ fold change (right) of KLF11 in human subcutaneous abdominal WAT from a total of 18 subjects treated for 3 mo with placebo and then 3 mo with rosiglitazone or vice versa. mRNA expression was normalized to control genes PPIA and PGK1. Details on the human cohort were previously described (Tan et al. 2005). Significance was determined using Wilcoxon matched pairs signed-ranks test. per se, they lead to further activation of KLF11 along with the brite-selective gene program in brite hMADS adipocytes.

Next, we examined whether rosiglitazone treatment of human adults has any effect on KLF11 expression in subcutaneous fat. For this purpose, we used a human cohort consisting of $18 \mathrm{~T} 2 \mathrm{D}$ patients treated with rosiglitazone for $90 \mathrm{~d}$ (Tan et al. 2005). Interestingly, rosiglitazone treatment leads to a statistically significant induction of KLF11 expression in abdominal subcutaneous fat of T2D subjects compared with placebo treatment (Fig. 4E). UCP1 expression was below the detection limit in 16 out of 18 placebo-treated individuals in this cohort; however, upon $90 \mathrm{~d}$ of rosiglitazone treatment, UCP1 expression became detectable in eight out of 18 T2D patients (Supplemental Fig. S8G), suggesting that some degree of browning occurs in the subcutaneous fat in response to rosiglitazone. Taken together, this demonstrates that KLF11 is a direct PPAR $\gamma$ target gene that is induced by rosiglitazone during in vitro as well as in vivo browning of human adipocytes.

\section{KLF11 specifically activates the brite adipocyte gene program}

We next addressed whether KLF11 plays an active role in the regulation of the human brite adipocyte gene program. Using two different lentiviral shRNA constructs, we found that knockdown of KLF11 in mature hMADS adipocytes significantly inhibits the induction of UCP1 upon rosiglitazone stimulation (Fig. 5A,B). In contrast, knockdown of a white-selective factor, ZNF323, resulted in a robust induction of UCP1 mRNA expression compared with the scramble control (Supplemental Fig. S9A). Consistent with the effect on UCP1 expression, we found that a subset of functionally important brite-selective genes is significantly repressed by KLF11 knockdown, whereas a control group consisting of white and general adipocyte marker genes is not (Fig. 5B). Importantly, PPAR $\gamma$ expression is comparable in control cells and cells with knockdown of KLF11, demonstrating that the effect on brite-selective gene expression is not mediated by feedback regulation of PPAR $\gamma$ (Fig. 5A,B). Interestingly, the gene encoding FHL1 is also associated with a briteselective superenhancer (Supplemental Fig. S9B,C), and we show that FHL1, similar to KLF11, is required for browning (Supplemental Fig. S9D). This demonstrates that brite-selective superenhancers can be used as a discovery tool to identify key regulatory factors for the browning process.

Investigation of the global effect of KLF11 on the briteselective gene program by RNA-seq (Supplemental Fig. S10A) showed that a large fraction of brite-selective genes $(17.4 \%)$ is significantly repressed by KLF11 knockdown, whereas a significantly lower fraction $(4.3 \%)$ is induced. Furthermore, only minor fractions of white-selective and constitutively expressed genes are affected by KLF11 knockdown (Fig. 5C). These results indicate that KLF11 acts predominantly as an activator of the brite-selective gene program. Notably, functional enrichment analysis 
A
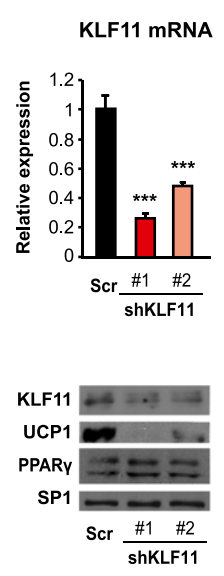

C

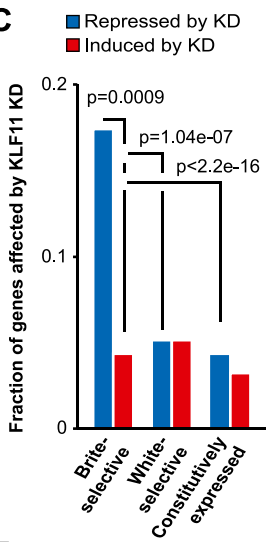

E

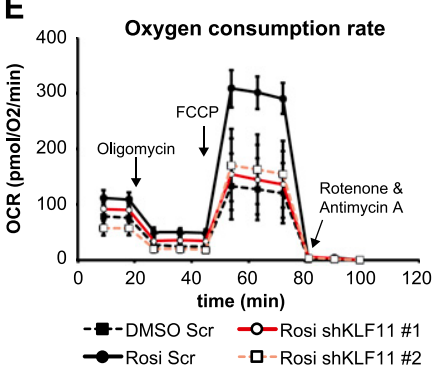

B

D
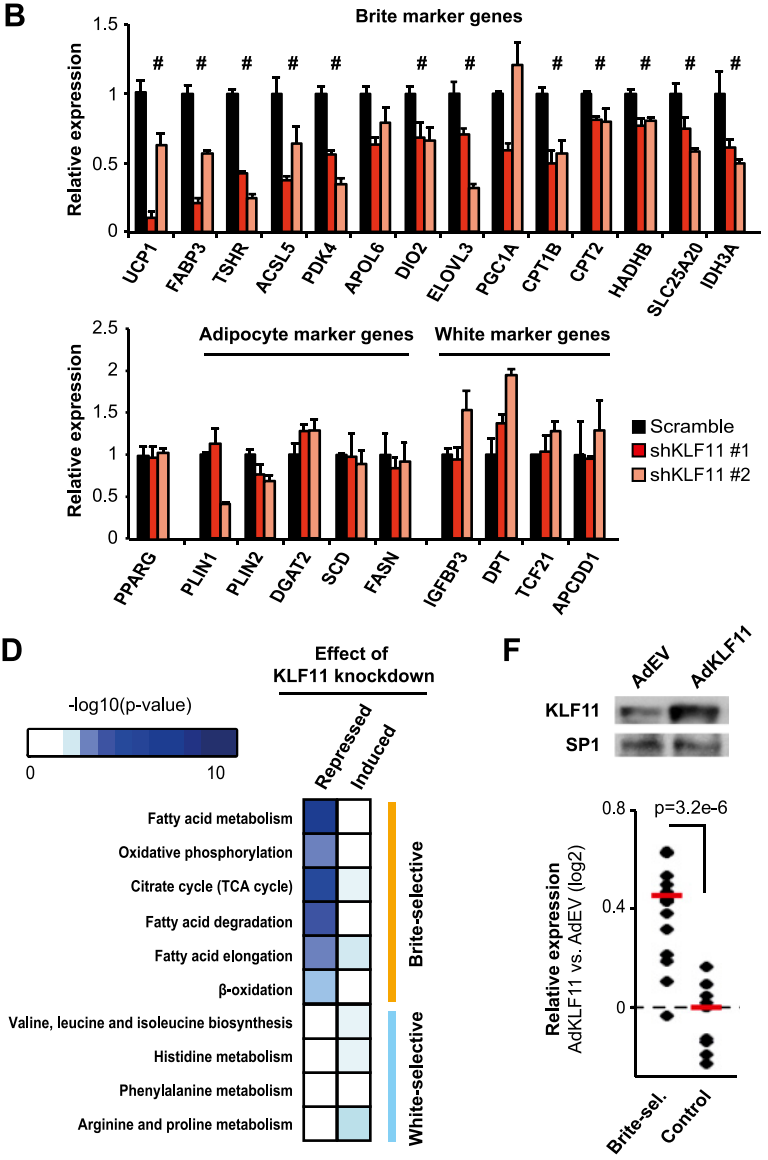

$\mathbf{F}$

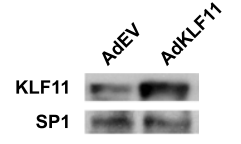

Figure 5. KLF11 specifically activates the brite adipocyte gene program. (A) KLF11 mRNA (top) and KLF11, UCP1, and PPAR $\gamma$ protein (bottom) expression in day $16 \mathrm{hMADS}$ adipocytes transduced with lentivirus expressing either scramble shRNA (black) or one of two different KLF11 shRNAs (red) at day 10. hMADS adipocytes were subsequently treated with rosiglitazone from day 13 to day 16. Error bars represent $\mathrm{SD}(n=3) .\left(^{\star \star \star}\right) P<0.001$ compared with scramble control. (B) Expression levels of brite (top) and white and general (bottom) adipocyte markers in hMADS adipocytes transduced with lentivirus and stimulated with rosiglitazone as described in $A$. Error bars represent $\mathrm{SD}(n=3)$. (\#) $P$-value < 0.02 for both lentiviral constructs compared with scramble control. $(C)$ Fraction of the top brite- and white-selective genes that are significantly (FDR $<0.1$ ) induced (red) or repressed (blue) by KLF11 knockdown. Significance was determined by Fisher's exact test as indicated. $(D)$ Genes either repressed or induced by KLF11 knockdown were subjected to functional enrichment analyses. Enrichment was tested for a subset of brite and white adipocyte-selective metabolic pathways as determined in Supplemental Table S1. $P$-values are illustrated in the heat map. (E) OCR in hMADS adipocytes transduced with lentivirus expressing either scramble shRNA (black) or two different KLF11 shRNA (red) at day 10 and subsequently treated with DMSO or rosiglitazone from day 13 to day 16. (Left) The arrows indicate time of addition for oligomycin, FCCP, and rotenone/antimycin A. (Right) Uncoupled, maximal, and basal respiration in scramble and KLF11 knockdown cells. Error bars represent SEM $(n=3)$. $\left.{ }^{*}\right) P<0.05$ as indicated. $(F)$ Rosiglitazonetreated hMADS adipocytes (day 15) were subjected to KLF11 adenovirus (AdKLF11) or empty adenoviral control (AdEV), and expression was evaluated $24 \mathrm{~h}$ after transduction. (Top) Overexpression of KLF11 was evaluated by Western blot. (Bottom) $\log _{2}$ fold change in gene expression in AdKLF11-treated cells compared with AdEV-treated cells for a subset of brite-selective genes as well as a control group of genes (as defined in $A, B$ ). The red lines represent the medians of the data sets. Significance was determined by Student's $t$-test.

revealed that the majority of genes repressed by KLF11 knockdown belong to brite-selective metabolic pathways (Supplemental Table S1), such as fatty acid metabolism and oxidative phosphorylation (Fig. 5D). Importantly, the ability of rosiglitazone to induce a higher oxygen consumption rate (OCR; i.e., basal, maximal, and uncoupled respiration) and fatty acid oxidation capacity is completely abolished by KLF11 knockdown (Fig. 5E; Supplemental Fig. S10B). Thus, KLF11 is required for the ability of rosiglitazone to induce a brite phenotype in hMADS adipocytes.

To investigate whether KLF11 is capable of further activating brite-selective genes, we modestly overexpressed KLF11 in brite hMADS adipocytes using an adenoviral vector (Fig. 5F) and evaluated the effects on the subset of genes examined in Figure 5, A and B. Interestingly, overexpression of KLF11 causes a significant increase in mRNA levels of the majority of these brite-selective genes (Fig. 5F; Supplemental Fig. S10C), whereas there is little effect on general and white adipocyte marker genes. Collectively, these results show that KLF11 plays an important and rate-limiting role in the induction of the brite-selective gene program and an oxidative phenotype in hMADS adipocytes.

\section{KLF11 induces brite-selective genes by activating nearby regulatory regions}

To address the question of whether KLF11 directly activates brite-selective genes, we investigated whether KLF11 
occupies sites in the vicinity of brite-selective genes regulated by KLF11. Antibody specificity was validated by KLF11 knockdown followed by ChIP-qPCR at selected sites (Supplemental Fig. S11A). Interestingly, we detected significant KLF11 binding in close proximity to several brite-selective genes, including UCP1, PDK4, FABP3, and $D I O 2$, in brite hMADS adipocytes (Fig. 6A). Genome-wide binding profiling of KLF11 in white and brite hMADS adipocytes identified a total of 38,391 binding sites. As reported for KLF1 (Pilon et al. 2011), KLF11 binding is most prominent at gene promoter regions, although robust binding to distal regions can also be detected (Fig. 6B). Importantly, however, there is a highly significant enrichment of a motif resembling the SP1/KLF motif in all of these groups, suggesting that KLF11 binds directly to both promoter and more distal sites (Supplemental Fig. S11B). Interestingly, KLF11 binding at PPAR $\gamma$ enhancer constituents within superenhancers in brite adipocytes is elevated compared with that at regular PPAR $\gamma$ enhancers (Fig. 6C), indicating that KLF11 is particularly associated with PPAR $\gamma$ in superenhancers. Coimmunoprecipitation of KLF11 and PPAR $\gamma$ in brite hMADS adipocytes showed that they are able to interact, indicating potential direct cooperativety between these
A

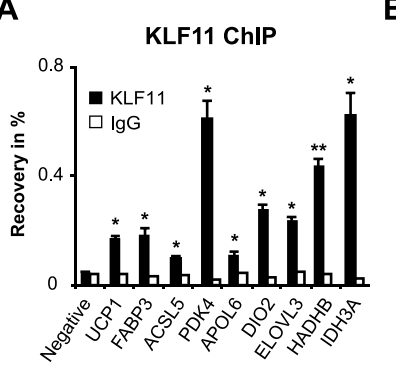

D

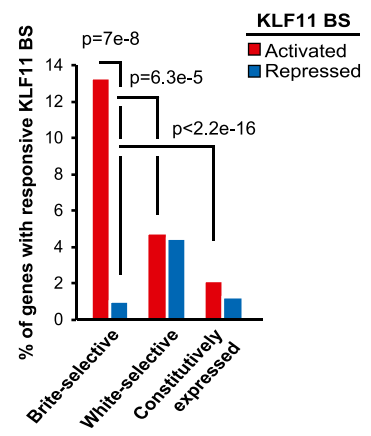

$\mathbf{F}$

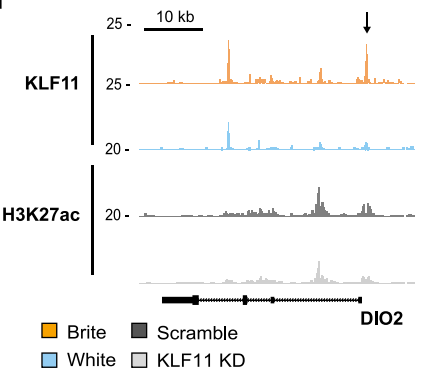

B

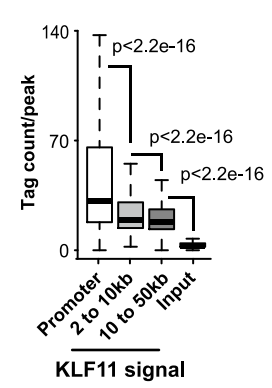

E

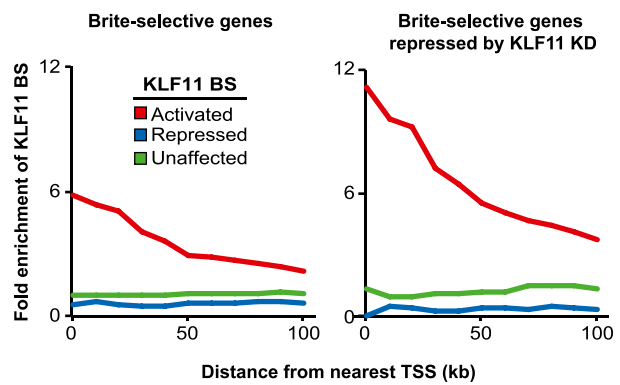

G

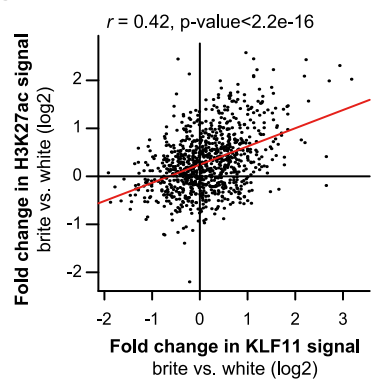

KLF11 signal in PPARY enhancers

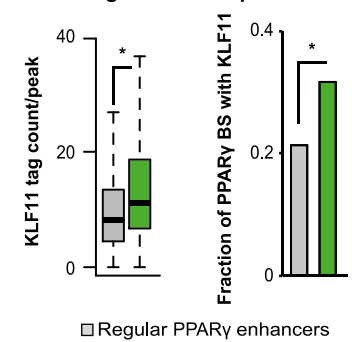
QRegular PPARy enhancers
पPPARY Super-enhancers

H KLF11-activated BS

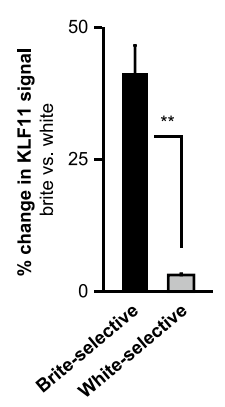

Figure 6. KLF11 is a direct activator of briteselective genes. (A) KLF11 binding to target sites in the vicinity of a subset of briteselective genes in brite hMADS adipocytes as determined by ChIP-qPCR. Binding of KLF11 (black) and IgG (white) to selected sites (UCP1 $-7 \mathrm{~kb}, F A B P 3-8.5 \mathrm{~kb}$, ACSL5 +7.3 kb, PDK4 promoter, APOL6 promoter, DIO2 promoter, ELOVL3 - $17.9 \mathrm{~kb}, H A D H B$ promoter, and $I D H 3 A$ promoter) expressed as the percentage of recovery compared with the input sample. A negative control region (without any binding of KLF11) is included. Error bars represent SEM $(n=3) .\left(^{\star}\right) P$-value < 0.05 compared with negative control. $(B)$ KLF11 signal (as tag count per peak in a 400-bp window) in KLF11-binding sites in promoter (white, 16,390 sites within $2 \mathrm{~kb}$ of the TSS), near distal (light gray, 4529 sites from $2 \mathrm{~kb}$ to $10 \mathrm{~kb}$ away from the TSS), and far distal (dark gray, 9680 sites from $10 \mathrm{~kb}$ to $50 \mathrm{~kb}$ away from the TSS) regions in brite hMADS adipocytes. Input signal in all KLF11binding sites is shown as a control (black). Significance was determined by Wilcoxon rank-sum test. (C) KLF11 signal (as tag count per peak in a 400-bp window) in PPAR $\gamma$ constituents (left) and the fraction of PPAR $\gamma$ constituents with KLF11 binding (right) in regular PPAR $\gamma$-binding regions (gray, 46,392 peaks) and PPAR $\gamma$ superenhancers (green, 5638 peaks) in brite hMADS adipocytes. $\left({ }^{*}\right)$ $P<2.2 \times 10^{-16}$ as indicated, Wilcoxon ranksum test (left panel) and Pearson's $\chi^{2}$ test (right panel). (D) Percentage of the top briteand white-selective genes as well as constitutively expressed genes (as defined in Fig. $1 \mathrm{E})$, that have a KLF11-activated (red, 1179 sites) or KLF11-repressed (blue, 489 sites)

binding site (BS) within $50 \mathrm{~kb}$ of the TSS. (E) Enrichment of KLF11-activated (red), KLF11-repressed (blue), or KLF11-unaffected (green, 1076 sites) binding sites (BS) near the top brite-selective genes (left) and the top brite-selective genes significantly repressed by KLF11 knockdown (right). Enrichment was determined as the number of binding sites per gene within different distances from the TSS (0-100 $\mathrm{kb})$ of regulated genes relative to the number of binding sites per gene of constitutively expressed genes as defined in Figure $1 \mathrm{E}$. $(F)$ ChIPseq binding profiles of KLF11 in white (light blue) and brite (orange) hMADS adipocytes as well as H3K27ac profiles in hMADS adipocytes transduced with shScramble (dark gray) or shKLF11 (light gray) from the DIO2 locus. The arrow indicates a putative KLF11-activated binding site. $(G)$ Correlation between the $\log _{2}$ fold change in KLF11 signal and H3K27ac signal in brite versus white hMADS adipocytes at $945 \mathrm{KLF} 11$-activated binding sites within $100 \mathrm{~kb}$ of annotated RefSeq genes. $r$ indicates Pearson's correlation coefficient, and the red line shows the linear regression between plotted values. $(H)$ Plot illustrating the mean percentage change in KLF11 signal in brite compared with white hMADS adipocytes at KLF11-activated binding sites within $100 \mathrm{~kb}$ of the top brite-selective (black) and white-selective (gray) genes. Error bars represent the $95 \%$ confidence interval around the mean. $\left(^{\star \star}\right) P$-value $<0.005$, two-tailed Student's test. 
two transcription factors (Supplemental Fig. S11C). In line with this, KLF11 knockdown reduces MED1 occupancy at a subset of shared PPAR $\gamma /$ KLF11-binding sites within brite-selective PPAR $\gamma$ superenhancers (Supplemental Fig. S11D), indicating that KLF11 affects the activity of at least a subset of PPAR $\gamma$ constituents within briteselective PPAR $\gamma$ superenhancers.

To identify the functionally most important KLF11binding sites, we performed H3K27ac ChIP-seq in hMADS adipocytes with or without KLF11 knockdown and evaluated the changes in H3K27ac signal upon KLF11 knockdown at all identified KLF11-binding sites. This allowed us to define subsets of KLF11-binding sites that either lose (1179 sites), gain (489 sites), or have unchanged (1076 sites) H3K27ac levels in response to KLF11 knockdown (Supplemental Fig. S12A); i.e., sites representing putative KLF11-activated, KLF11-repressed, and unaffected sites, respectively. Interestingly, the percentage of distal KLF11-binding sites affected by KLF11 knockdown is significantly higher than the percentage of promoterproximal sites affected, suggesting that KLF11 has a prominent effect on distal regions despite these being weaker binding sites (Supplemental Fig. S12B).

We next examined how these responsive KLF11-binding sites are related to brite- and white-selective gene programs. Interestingly, we found that the fraction of brite-selective genes associated with putative KLF11activated binding sites is significantly higher than the fraction of white-selective and constitutively expressed genes (Fig. 6D). Furthermore, putative KLF11-activated binding sites are enriched in the vicinity of brite-selective genes compared with KLF11-repressed and unaffected binding sites and are even more enriched near briteselective genes that are repressed by KLF11 knockdown (Fig. 6E). In contrast, such sites are not enriched near genes that are induced by KLF11 knockdown or near white-selective genes (Supplemental Fig. S12C). These results demonstrate that KLF11-activated sites are mainly linked to brite-selective genes (see Fig. 6F; Supplemental Fig. S12D for examples). Importantly, there is a positive correlation between changes in KLF11 signal and $\mathrm{H} 3 \mathrm{~K} 27 \mathrm{ac}$ signal during browning at KLF11-activated sites (Fig. 6G), with a specific gain of KLF11 and H3K27ac near brite-selective compared with white-selective genes
(Fig. 6H; Supplemental Fig. S12E). Cumulatively, these results indicate that KLF11 functions as a specific and direct transcriptional activator of a large subset of briteselective genes.

In summary, we present a model (Fig. 7) for rosiglitazone-mediated browning of human adipocytes and show the requirement for KLF11 in this process. In this model, rosiglitazone stimulation of mature human adipocytes triggers reprogramming of PPAR $\gamma$ binding, leading to the formation of brite-selective PPAR $\gamma$ superenhancers, which play an important role in activating the brite-selective gene program. This includes genes encoding browning transcription factors such as KLF11, which act in a cooperative manner with PPAR $\gamma$ to ensure full induction and maintenance of the brite adipocyte gene program independently of rosiglitazone.

\section{Discussion}

In this study, we used for the first time a genome-wide approach to characterize the transcriptional reprogramming events associated with the formation of functional human brown-like adipocytes. Using rosiglitazone as a browning stimulus, we show that comprehensive transcriptional changes occur during the browning process to establish a stable brite adipocyte gene program that, once established, can be maintained independently of rosiglitazone. Thus, it appears that the prolonged rosiglitazone stimulus induces an alternatively committed differentiation state in hMADS cells, where the adipocytes remain brite even when the stimulus has been withdrawn. This indicates that additional "stabilizing" browning factors are induced by rosiglitazone and are required for maintenance of browning.

Interestingly, rosiglitazone is also used in the differentiation cocktail from day 3 to day 9 of hMADS differentiation, at which point browning is not induced. It is unclear why only mature white adipocytes are able to undergo browning in response to rosiglitazone, but it is likely that activation of the browning genes requires factors that are not expressed until late in the differentiation of white adipocytes.

Despite considerable changes in gene expression during browning, the genome-wide changes in DHS are modest.
Mature white adipocytes Rosiglitazone-induced activation of genes encoding browning factors
Stable rosiglitazone-independent brite adipocytes

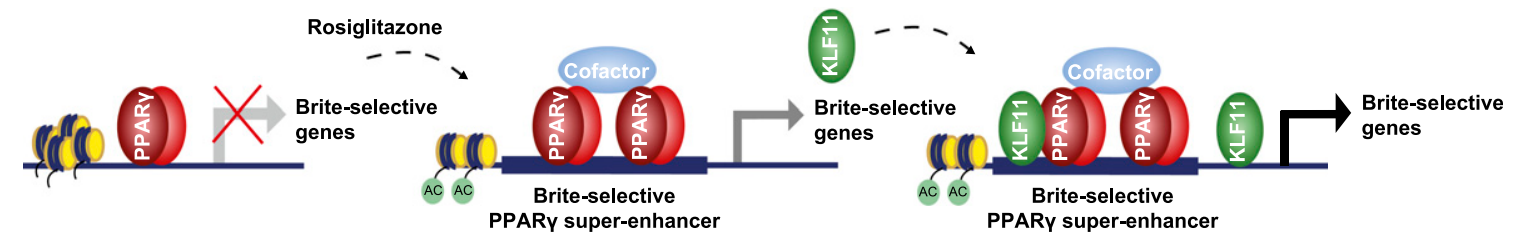

Figure 7. Model for rosiglitazone-induced browning and the role of KLF11 in this process. Rosiglitazone stimulation of mature human adipocytes leads to reprogramming of PPAR $\gamma$ binding, resulting in the formation of brite-selective PPAR $\gamma$ superenhancers. These events stimulate the expression of brite-selective genes, including the transcriptional regulator KLF11. Once induced, KLF11 acts in a cooperative manner with PPAR $\gamma$ and other browning factors to ensure full induction and maintenance of the brite adipocyte gene program independently of rosiglitazone. 
This is in sharp contrast to the dramatic changes in chromatin structure (Siersbæk et al. 2011; Waki et al. 2011) and epigenomic marks (Mikkelsen et al. 2010; Steger et al. 2010) during 3T3-L1 adipocyte differentiation and indicates that transcriptional changes during browning of hMADS cells occur without major global changes in the chromatin landscape. Instead, our results indicate that browning relies on changes of the activity of a small subset of enhancers, possibly combined with modest changes in the activity of additional enhancers.

The fact that browning is induced by rosiglitazone indicated that PPAR $\gamma$ could be a major driver of the genomic reprogramming during browning, and we therefore profiled PPAR $y$ in white and brite hMADS adipocytes. We showed that only a small fraction of PPAR $\gamma$-binding sites differs dramatically in PPAR $\gamma$ occupancy, indicating that $\operatorname{PPAR} \gamma$ acts in a site-selective manner and that the majority of PPAR $\gamma$ functions are common between white and brite adipocytes. Similarly, $\operatorname{PPAR} \gamma$ binding in in vitro differentiated primary adipocytes obtained from different mouse white and brown adipose depots differs only at a subset of sites (Siersbæk et al. 2012). Importantly, and consistent with a central role of PPAR $\gamma$ in genomic reprogramming, we show that reprogrammed brite-selective PPAR $\gamma$-binding sites correspond to sites that gain enhancer activity during browning, and these sites are enriched in the vicinity of brite-selective genes.

Interestingly, reprogramming of PPAR $\gamma$ binding during browning leads to the formation of brite-selective superenhancers (i.e., clusters of individual enhancers) recently shown to be key drivers of gene programs that define cell identify (Loven et al. 2013; Whyte et al. 2013). It appears that reprogramming of PPAR $\gamma$ binding at single constituent enhancers plays a major role in redefining PPAR $\gamma$ superenhancers during browning. Importantly, we show that brite-selective PPAR $\gamma$ superenhancers are much more enriched near brite-selective genes than regular brite-selective PPAR $\gamma$ enhancers. Furthermore, briteselective genes associated with brite-selective superenhancers are more dramatically induced during browning than genes that do not have brite-selective superenhancers nearby. This clearly indicates the importance of superenhancers in defining gene programs characteristic of different adipocyte subtypes. The brite-selective superenhancers are enriched near genes encoding important metabolic regulators involved in fatty acid degradation and $\beta$-oxidation.

Since superenhancers have been reported to be associated with genes encoding lineage-determining transcriptional regulators (Whyte et al. 2013), we examined the list of genes associated with brite-selective PPAR $\gamma$ superenhancers. Interestingly, both factors that were chosen for analysis, KLF11 and FHL1, were found to be required for browning, demonstrating that association with superenhancers can be used as a discovery tool to identify novel transcriptional regulators of browning of adipocytes. Here we selected KLF11, which is a member of the SP1/KLF family of transcription factors, for further analyses. KLFs constitute an interesting family of tran- scription factors involved in the regulation of diverse metabolic networks (Neve et al. 2005; Lomberk et al. 2013; Zhang et al. 2013). Several KLF family members, including KLF2, KLF3, KLF4, KLF5, KLF6, KLF7, KLF9, and KLF15, have been implicated in different stages of adipogenesis (Wu and Wang 2013), but a role of KLF11 in adipogenesis has not been described. KLF11 has been shown to activate UCP1 expression in mouse bone marrow-derived stem cells (Yamamoto et al. 2010); however, the impact of KLF11 on browning of adipocytes remains unknown.

Our results identify KLF11 as a novel PPAR $\gamma$ target gene in human adipocytes, presumably activated through the nearby PPAR $\gamma$ superenhancer. Importantly, we show by loss of function and gain of function that KLF11 is a selective global activator of the brite adipocyte gene program in human adipocytes. To our knowledge, this places KLF1 1 as the first PPAR $\gamma$-induced sequence-specific transcription factor involved in browning. Thus, KLF11 acts as a direct molecular link between the acute rosiglitazone-induced gene program and stabilization of the brite adipocyte phenotype. Cofactors that may contribute to this link include PGC- $1 \alpha$, which is a PPAR $\gamma$ target gene in primary cultures of white and brown adipocytes (Hondares et al. 2006), and PRDM16, which has been shown to be activated by PPAR $\gamma$ through increased stability $/ \mathrm{Ohno}$ et al. 2012). Interestingly, our data show that KLF11 can be further induced by cooling and $\beta$-adrenergic stimulation of brite hMADS adipocytes, suggesting that KLF11 might be involved in mediating alternative thermogenic stimuli in addition to rosiglitazone-induced browning. In support of this notion, examination of microarray data from mice subjected to cold for $10 \mathrm{~d}$ (Rosell et al. 2014) revealed that KLF11 expression is induced in subcutaneous WAT as part of the cold response involving thermogenic and oxidative genes. In line with what has previously been shown (Elabd et al. 2009; Jespersen et al. 2013), neither $\beta$-adrenergic stimulation nor cooling of white hMADS adipocytes is capable of inducing browning, suggesting that additional activation stimuli are needed for induction of a thermogenic response in human white adipocytes.

Browning of human adipose tissue in response to cold has been shown to contribute significantly to human metabolism (Ouellet et al. 2012; Yoneshiro et al. 2013), and it is likely that rosiglitazone-induced browning of human adipose tissue could have a similar effect (Bogacka et al. 2005). Interestingly, our results show that KLF11 expression is induced by rosiglitazone in abdominal subcutaneous adipose tissue of human T2D subjects and that this is paralleled by an induction of UCP1 to detectable levels in eight out of 18 subjects. Thus, in addition to the weight gain experienced in subjects treated with rosiglitazone in this cohort (Tan et al. 2005), our data indicate that at least a subset of these patients displayed modest browning of their subcutaneous adipose tissue in response to rosiglitazone.

Genome-wide profiling of KLF11 demonstrates that KLF11 is primarily associated with promoter-proximal regions, which is in line with results for another member of the SP1/KLF family, KLF1 (Pilon et al. 2011). Since 
KLF11 has been reported to have both Sin3-HDACdependent and HP1-HMT-dependent repressor functions as well as p300-induced activation properties (Zhang et al. 2001; Fernandez-Zapico et al. 2009; Lomberk et al. 2012; Seo et al. 2012), we grouped the KLF11-binding sites into putative KLF11-activated sites (loss of H3K27ac in response to KLF11 knockdown) and putative KLF11-repressed sites (gain of H3K27ac in response to KLF11 knockdown). Our results demonstrate that putative KLF11-activated binding sites are highly enriched in the vicinity of brite-selective genes, in particular putative KLF11-activated brite-selective genes. A similar enrichment of KLF11-repressed sites was not observed for genes activated by loss of KLF11. This indicates that, in terms of the browning process, KLF11 acts primarily as a direct activator of the brite gene program.

In conclusion, we show for the first time that rosiglitazone-induced browning of human adipocytes is associated with comprehensive changes in gene expression driven in part by brite-selective PPAR $\gamma$ superenhancers. Furthermore, we identify KLF11 as a novel browning factor and a direct PPAR $y$ target gene that is required for rosiglitazone-induced browning of human adipocytes. Thus, KLF11 constitutes a novel molecular link between the rosiglitazone-induced gene expression and the activation and maintenance of the brite-selective gene program. We propose that activation of KLF11 and other browning factors cooperate with PPAR $\gamma$ to establish a "stable" brite phenotype independent of continued administration of rosiglitazone. Future studies should investigate the molecular cross-talk between PPAR $\gamma$ and such browning factors.

\section{Materials and methods}

\section{hMADS cell culturing and differentiation}

hMADS-3 cells (Rodriguez et al. 2005; Zaragosi et al. 2007) were cultured and differentiated into mature adipocytes as described in the Supplemental Material. From day 13 to day 16 of differentiation, hMADS adipocytes were treated with rosiglitazone to form brite adipocytes or with DMSO to maintain white adipocytes. From day 16 forward, the differentiation medium of both white and brite adipocytes was depleted for rosiglitazone. GW9662 (Sigma) at $0.5 \mu \mathrm{M}$ and isoproterenol (Sigma) at $1 \mu \mathrm{M}$ were applied to the cell cultures as indicated.

\section{Oil-red-O staining and glycerol-3-phosphate dehydrogenase analysis}

Oil-red-O staining was performed as previously described (Helledie et al. 2002). Spectrophotometric analysis was used for quantification by measuring optical density at $500 \mathrm{~nm}$. Glycerol-3-phosphate dehydrogenase activity measurements were performed as previously described (Negrel et al. 1978).

\section{RNA extraction, cDNA synthesis, and quantitative real-time PCR}

RNA extraction, cDNA synthesis, and quantitative real-time PCR were performed as previously described (Nielsen et al. 2006). Data were normalized to TBP unless stated otherwise. Sequences of real-time PCR primers will be provided on request. Two-tailed Student's $t$-test was used to determine significance.

\section{Western blotting and ECL detection}

Whole-cell extracts were prepared in SDS-containing buffer and subjected to Western blotting as previously described (Nielsen et al. 2006). The following antibodies were used: anti-PPAR $\gamma$ (E-8; sc-7273, Santa Cruz Biotechnology), anti-KLF11 (10D8; H00008462-M03, Novus Biologicals), anti-FHL1 (10991-1-AP, Proteintech), anti-UCP1 (ab10983, Abcam), anti-Omni-probe (D8; sc-7270, Santa-Cruz Biotechnology), anti-rabbit IgG (P0399, DAKO), and anti-mouse IgG (P0447, DAKO). Anti-SP1 (sc-17824, Santa-Cruz Biotechnology) or anti-TFIIB (sc-225, Santa Cruz Biotechnology) was included as a loading control. Densitometry was used to quantify protein expression, and a two-tailed Student's $t$-test was used to determine significance.

\section{Lentiviral production and transduction of hMADS cells}

For knockdown of PPAR $\gamma$ (Nielsen et al. 2008), KLF11, FHL1, and ZNF323 shRNA oligos targeting these factors were cloned into pSicoR PGK puro vectors (Addgene), and lentiviral particles were produced in human embryonic kidney (HEK) 293T cells as described (Ventura et al. 2004). As a control, a shRNA nontargeting oligo (scramble) was used. Sequences of shRNA oligos will be provided on request. Mature hMADS adipocytes (day 10 after induction of differentiation) were incubated for $24 \mathrm{~h}$ with lentiviral medium containing $6 \mu \mathrm{g} / \mathrm{mL}$ polybrene (Sigma) before the medium was changed to normal differentiation medium. shKLF11 construct \#1 was used for RNA-seq experiments.

\section{Adenoviral overexpression}

The generation of the (His ${ }_{6}$-Xpress) KLF11 and control adenoviral vectors (Ad5CMV) was described in Lomberk et al. (2012). Rosiglitazone-treated hMADS adipocytes at day 15 were transduced for $6 \mathrm{~h}$ with $\sim 8 \times 10^{9}$ infectious units of adenoviral particles per milliliter and $1 \mu \mathrm{g} / \mathrm{mL}$ poly-L-lysine in DMEM (Sigma). After the initial incubation, the medium was changed to normal differentiation medium without rosiglitazone, and cells were harvested $18 \mathrm{~h}$ later.

\section{$\beta$-Oxidation}

Determination of $\beta$-oxidation capacity in day 16 hMADS adipocytes transduced with lentivirus as described above was performed essentially as previously described (Berge et al. 2003).

\section{Mitochondrial respiration analyses}

For mitochondrial respiration analysis, hMADS cells were seeded in 24 multiwell plates (Seahorse) and differentiated and/ or transduced with lentivirus as previously described. OCR in hMADS adipocytes at day 16 or 19 was determined using an XF24 extracellular flux analyzer (Seahorse Bioscience). We added $1.2 \mu \mathrm{M}$ oligomycin, $1 \mu \mathrm{M}$ FCCP, $1 \mu \mathrm{M}$ rotenone, and $1 \mu \mathrm{M}$ antimycin A to the cells as indicated.

\section{Coimmunoprecipitation}

Nucleus extraction and coimmunoprecipitation were performed essentially as described (Siersbaek et al. 2014). In brief, nuclei were isolated from rosiglitazone-treated hMADS adipocytes transduced with AdEV or His-tagged AdKLF11 as described above. Cleared nuclear extract was subjected to coimmunoprecipitation overnight at $4^{\circ} \mathrm{C}$ using anti-Omni-probe (D8; SantaCruz Biotechnology, sc-7270) conjugated to agarose beads. After washing, the immunoprecipitates were eluted by boiling in SDS buffer and subsequently prepared for Western blotting. 


\section{RNA-seq}

Five micrograms of total RNA from hMADS preadipocytes and mature day 19 white and brite adipocytes was treated with a Ribo-Zero rRNA removal kit (Epicentre) and subjected to fragmentation and cDNA synthesis using the TruSeq RNA sample preparation kit version 2 (Illumina).

\section{ChIP}

ChIP experiments were performed in white and brite hMADS adipocytes at day 19 essentially as previously described (Siersbæk et al. 2012). For cross-linking of chromatin, $0.2 \mathrm{mM}$ disuccinimidyl glutarate (DSG) (Proteochem) was applied for $45 \mathrm{~min}$ followed by cross-linking using $1 \%$ formaldehyde for $10 \mathrm{~min}$. The antibodies used were anti-PPAR $\gamma$ (H-100; sc-7196, Santa Cruz Biotechnology), anti-MED1 (M-255; sc-8998, Santa Cruz Biotechnology), anti-CBP (A-22; sc-369, Santa Cruz Biotechnology), anti-KLF11 (10D8; H00008462-M03, Novus Biologicals), and anti-H3K27ac (ab4729, Abcam).

\section{DHS site assessment}

DNase I digestion was performed in white and brite hMADS adipocytes at day 19 on $\sim 10$ million nuclei essentially as previously described (Siersbæk et al. 2011).

\section{Library construction}

RNA-seq, DHS-seq, and ChIP-seq libraries were constructed according to the manufacturer's instructions (Illumina) as described (Nielsen and Mandrup 2014). Sequencing was performed on our in-house Illumina platform.

\section{Data analyses}

RNA-seq data RNA reads were aligned to the human reference genome (version hg19) using Bowtie2 (Langmead and Salzberg 2012). The number of exon reads for all RefSeq genes was counted using Subread (Liao et al. 2013), and differential expression was determined using DESeq2 (Love et al. 2014). Functional enrichment analysis was performed with HOMER (Heinz et al. 2010) using pathways related to metabolism from the Kyoto Encyclopedia of Genes and Genomes (KEGG) annotation (Kanehisa and Goto 2000; Kanehisa et al. 2014)

Alignment of ChIP-seq and DHS-seq data, peak calling, and identification of regions with differential signal intensity Sequence tags were aligned to the human reference genome (hg19) using Bowtie (Langmead et al. 2009), and ChIP-seq peaks were called using HOMER (Heinz et al. 2010). The University of California at Santa Cruz Genome Browser (Kent et al. 2002) was used for visualization. The differential signal intensity in binding regions/superenhancers was determined using HOMER and EdgeR (Robinson et al. 2010).

Accession numbers Sequencing data are available from the Gene Expression Omnibus (GEO) under accession number GSE59703.

\section{Human subjects}

Human subcutaneous abdominal fat biopsies from a double-blind, placebo-controlled, crossover study involving T2D subjects treated with placebo/rosiglitazone for $90 \mathrm{~d}$ were used to analyze KLF11 expression. A total of 18 subjects from whom a complete physiological data set is available was included. Details on subjects and procedures were as described previously (Tan et al.
2005). Significance was determined using a Wilcoxon matched pairs signed-ranks test.

Additional information is available in the Supplemental Material.

\section{Acknowledgments}

We thank Rasmus Siersbæk and Niels Mahler Kristiansen as well as other members of the Mandrup laboratory for experimental support and fruitful discussions. Furthermore, we are grateful to Christian Dani (Université de Nice Sophia-Antipolis) for providing hMADS cells, and Per Sauerberg (Novo Nordisk A/S) for the kind gift of rosiglitazone. Work in the Mandrup laboratory was supported by grants from the VILLUM Foundation to the VILLUM Center for Bioanalytical Sciences at University of Southern Denmark, the Lundbeck Foundation, the Novo Nordisk Foundation, and the Danish Independent Research Council/ Natural Sciences. Work in the Amri laboratory was supported by grants from the EU FP7 project DIABAT (HEALTH-F2-2011278373), and the Centre National de la Recherche Scientifique (CNRS). A.L. and I.F. were supported in part by a Novo Scholarship. A.L., M.S.S., and S.M. conceived and designed the study. A. L., I.F., M.S.S., S.F.S., A.-S.B.L., D.F.P., and R.N. performed the experiments. A.L., J.G.S.M., and M.M.A. performed computational analyses. A.M., M.J.N., R.U., F.K., and E.-Z.A. contributed samples and materials. A.L. and S.M. wrote the manuscript with input from the other authors.

\section{References}

Berge K, Tronstad K, Bohov P, Madsen L, Berge R. 2003. Impact of mitochondrial $\beta$-oxidation in fatty acid-mediated inhibition of glioma cell proliferation. J Lipid Res 44: 118-127.

Bogacka I, Xie H, Bray G, Smith S. 2005. Pioglitazone induces mitochondrial biogenesis in human subcutaneous adipose tissue in vivo. Diabetes 54: 1392-1399.

Bonnefond A, Lomberk G, Buttar N, Busiah K, Vaillant E, Lobbens S, Yengo L, Dechaume A, Mignot B, Simon A, et al. 2011. Disruption of a novel Kruppel-like transcription factor p300-regulated pathway for insulin biosynthesis revealed by studies of the c.-331 INS mutation found in neonatal diabetes mellitus. J Biol Chem 286: 28414-28424.

Cohen P, Levy JD, Zhang Y, Frontini A, Kolodin DP, Svensson KJ, Lo JC, Zeng X, Ye L, Khandekar MJ, et al. 2014. Ablation of PRDM16 and beige adipose causes metabolic dysfunction and a subcutaneous to visceral fat switch. Cell 156: 304-316.

Cousin B, Cinti S, Morroni M, Raimbault S, Ricquier D, Penicaud L, Casteilla L. 1992. Occurrence of brown adipocytes in rat white adipose tissue: molecular and morphological characterization. J Cell Sci 103: 931-942.

Crawford G, Holt I, Whittle J, Webb B, Tai D, Davis S, Margulies E, Chen Y, Bernat J, Ginsburg D, et al. 2006. Genome-wide mapping of DNase hypersensitive sites using massively parallel signature sequencing (MPSS). Genome Res 16: 123-131.

Creyghton M, Cheng A, Welstead G, Kooistra T, Carey B, Steine E, Hanna J, Lodato M, Frampton G, Sharp P, et al. 2010. Histone H3K27ac separates active from poised enhancers and predicts developmental state. Proc Natl Acad Sci 107: 21931-21936.

Cypess A, Lehman S, Williams G, Tal I, Rodman D, Goldfine A, Kuo F, Palmer E, Tseng Y-H, Doria A, et al. 2009. Identification and importance of brown adipose tissue in adult humans. N Engl J Med 360: 1509-1517.

Cypess AM, White AP, Vernochet C, Schulz TJ, Xue R, Sass CA, Huang TL, Roberts-Toler C, Weiner LS, Sze C, et al. 2013. Anatomical localization, gene expression profiling and func- 
tional characterization of adult human neck brown fat. Nat Med 19: 635-639.

Digby J, Montague C, Sewter C, Sanders L, Wilkison W, O'Rahilly S, Prins J. 1998. Thiazolidinedione exposure increases the expression of uncoupling protein 1 in cultured human preadipocytes. Diabetes 47: 138-141.

Elabd C, Chiellini C, Carmona M, Galitzky J, Cochet O, Petersen R, Pénicaud L, Kristiansen K, Bouloumié A, Casteilla L, et al. 2009. Human multipotent adipose-derived stem cells differentiate into functional brown adipocytes. Stem Cells 27: 2753-2760.

Feldmann HM, Golozoubova V, Cannon B, Nedergaard J. 2009. UCP1 ablation induces obesity and abolishes diet-induced thermogenesis in mice exempt from thermal stress by living at thermoneutrality. Cell Metab 9: 203-209.

Fernandez-Zapico ME, van Velkinburgh JC, Gutierrez-Aguilar R, Neve B, Froguel P, Urrutia R, Stein R. 2009. MODY7 gene, $\mathrm{KLF} 11$, is a novel p300-dependent regulator of Pdx-1 (MODY4) transcription in pancreatic islet $\beta$ cells. I Biol Chem 284: 36482-36490.

Fukui Y, Masui S, Osada S, Umesono K, Motojima K. 2000. A new thiazolidinedione, NC-2100, which is a weak PPAR- $\gamma$ activator, exhibits potent antidiabetic effects and induces uncoupling protein 1 in white adipose tissue of KKAy obese mice. Diabetes 49: 759-767.

Guerra C, Koza R, Yamashita H, Walsh K, Kozak L. 1998. Emergence of brown adipocytes in white fat in mice is under genetic control.Effects on body weight and adiposity. I Clin Invest 102: 412-420.

Haakonsson AK, Stahl Madsen M, Nielsen R, Sandelin A, Mandrup S. 2013. Acute genome-wide effects of rosiglitazone on PPAR $\gamma$ transcriptional networks in adipocytes. Mol Endocrinol 27: 1536-1549.

Harms M, Seale P. 2013. Brown and beige fat: development, function and therapeutic potential. Nat Med 19: 1252-1263.

Heintzman N, Hon G, Hawkins R, Kheradpour P, Stark A, Harp L, Ye Z, Lee L, Stuart R, Ching C, et al. 2009. Histone modifications at human enhancers reflect global cell-typespecific gene expression. Nature 459: 108-112.

Heinz S, Benner C, Spann N, Bertolino E, Lin Y, Laslo P, Cheng J, Murre C, Singh H, Glass C. 2010. Simple combinations of lineage-determining transcription factors prime cis-regulatory elements required for macrophage and B cell identities. Mol Cell 38: $576-589$.

Helledie T, Grontved L, Jensen SS, Kiilerich P, Rietveld L, Albrektsen T, Boysen MS, Nohr J, Larsen LK, Fleckner J, et al. 2002. The gene encoding the acyl-CoA-binding protein is activated by peroxisome proliferator-activated receptor $\gamma$ through an intronic response element functionally conserved between humans and rodents. I Biol Chem 277: 2682126830.

Himms-Hagen J, Cui J, Danforth E Jr, Taatjes DJ, Lang SS, Waters BL, Claus TH. 1994. Effect of CL-316,243, a thermogenic $\beta 3$-agonist, on energy balance and brown and white adipose tissues in rats. Am J Physiol 266: R1371-R1382.

Hondares E, Mora O, Yubero P, Rodriguez de la Concepcion M, Iglesias R, Giralt M, Villarroya F. 2006. Thiazolidinediones and rexinoids induce peroxisome proliferator-activated receptor-coactivator (PGC)-1 $\alpha$ gene transcription: an autoregulatory loop controls PGC- $1 \alpha$ expression in adipocytes via peroxisome proliferator-activated receptor- $\gamma$ coactivation. Endocrinology 147: 2829-2838.

Ishibashi J, Seale P. 2010. Medicine. Beige can be slimming. Science 328: 1113-1114.

Jespersen NZ, Larsen TJ, Peijs L, Daugaard S, Homoe P, Loft A de Jong J, Mathur N, Cannon B, Nedergaard J, et al. 2013. A classical brown adipose tissue mRNA signature partly over- laps with brite in the supraclavicular region of adult humans. Cell Metab 17: 798-805.

Kagey MH, Newman JJ, Bilodeau S, Zhan Y, Orlando DA, van Berkum NL, Ebmeier CC, Goossens I, Rahl PB, Levine SS, et al. 2010. Mediator and cohesin connect gene expression and chromatin architecture. Nature 467: 430-435.

Kanehisa M, Goto S. 2000. KEGG: Kyoto encyclopedia of genes and genomes. Nucleic Acids Res 28: 27-30.

Kanehisa M, Goto S, Sato Y, Kawashima M, Furumichi M, Tanabe M. 2014. Data, information, knowledge and principle: back to metabolism in KEGG. Nucleic Acids Res 42: D199-D205.

Kent WI, Sugnet CW, Furey TS, Roskin KM, Pringle TH, Zahler AM, Haussler D. 2002. The human genome browser at UCSC. Genome Res 12: 996-1006.

Kopecky J, Clarke G, Enerback S, Spiegelman B, Kozak LP. 1995. Expression of the mitochondrial uncoupling protein gene from the aP2 gene promoter prevents genetic obesity. I Clin Invest 96: 2914-2923.

Langmead B, Salzberg SL. 2012. Fast gapped-read alignment with Bowtie 2. Nat Methods 9: 357-359.

Langmead B, Trapnell C, Pop M, Salzberg SL. 2009. Ultrafast and memory-efficient alignment of short DNA sequences to the human genome. Genome Biol 10: R25.

Lefterova M, Zhang Y, Steger D, Schupp M, Schug I, Cristancho A, Feng D, Zhuo D, Stoeckert C, Liu X, et al. 2008. PPAR $\gamma$ and C/EBP factors orchestrate adipocyte biology via adjacent binding on a genome-wide scale. Genes Dev 22: 2941-2952.

Lefterova MI, Haakonsson AK, Lazar MA, Mandrup S. 2014. PPAR $\gamma$ and the global map of adipogenesis and beyond. Trends Endocrinol Med 25: 293-302.

Liao Y, Smyth GK, Shi W. 2013. The subread aligner: fast, accurate and scalable read mapping by seed-and-vote. Nucleic Acids Res 41: e108.

Lidell ME, Betz MJ, Dahlqvist Leinhard O, Heglind M, Elander L, Slawik M, Mussack T, Nilsson D, Romu T, Nuutila P, et al. 2013. Evidence for two types of brown adipose tissue in humans. Nat Med 19: 631-634.

Lomberk G, Mathison AJ, Grzenda A, Seo S, DeMars CJ, Rizvi S, Bonilla-Velez J, Calvo E, Fernandez-Zapico ME, Iovanna J, et al. 2012. Sequence-specific recruitment of heterochromatin protein 1 via interaction with Kruppel-like factor 11, a human transcription factor involved in tumor suppression and metabolic diseases. I Biol Chem 287: 13026-13039.

Lomberk G, Grzenda A, Mathison A, Escande C, Zhang JS, Calvo E, Miller LJ, Iovanna J, Chini EN, Fernandez-Zapico ME, et al. 2013. Kruppel-like factor 11 regulates the expression of metabolic genes via an evolutionarily conserved protein interaction domain functionally disrupted in maturity onset diabetes of the young. I Biol Chem 288: 1774517758.

Love MI, Huber W, Anders S. 2014. Moderated estimation of fold change and dispersion for RNA-seq data with DESeq2. bioRxiv. doi: 10.1101/002832.

Loven J, Hoke HA, Lin CY, Lau A, Orlando DA, Vakoc CR, Bradner JE, Lee TI, Young RA. 2013. Selective inhibition of tumor oncogenes by disruption of super-enhancers. Cell 153: 320-334.

Mikkelsen T, Xu Z, Zhang X, Wang L, Gimble J, Lander E, Rosen E. 2010. Comparative epigenomic analysis of murine and human adipogenesis. Cell 143: 156-169.

Negrel R, Grimaldi P, Ailhaud G. 1978. Establishment of preadipocyte clonal line from epididymal fat pad of ob/ob mouse that responds to insulin and to lipolytic hormones. Proc Natl Acad Sci 75: 6054-6058. 
Neve B, Fernandez-Zapico ME, Ashkenazi-Katalan V, Dina C, Hamid YH, Joly E, Vaillant E, Benmezroua Y, Durand E, Bakaher N, et al. 2005. Role of transcription factor KLF11 and its diabetes-associated gene variants in pancreatic $\beta$ cell function. Proc Natl Acad Sci 102: 4807-4812.

Nielsen R, Mandrup S. 2014. Genome-wide profiling of transcription factor binding and epigenetic marks in adipocytes by ChIP-seq. Methods Enzymol 537: 261-279.

Nielsen R, Grøntved L, Stunnenberg H, Mandrup S. 2006. Peroxisome proliferator-activated receptor subtype- and cell-type-specific activation of genomic target genes upon adenoviral transgene delivery. Mol Cell Biol 26: 56985714.

Nielsen R, Pedersen T, Hagenbeek D, Moulos P, Siersbaek R, Megens E, Denissov S, Børgesen M, Francoijs K-J, Mandrup S, et al. 2008. Genome-wide profiling of PPAR $\gamma:$ RXR and RNA polymerase II occupancy reveals temporal activation of distinct metabolic pathways and changes in RXR dimer composition during adipogenesis. Genes Dev 22: 2953-2967.

Ohno H, Shinoda K, Spiegelman B, Kajimura S. 2012. PPAR $\gamma$ agonists induce a white-to-brown fat conversion through stabilization of PRDM16 protein. Cell Metab 15: 395-404.

Ouellet V, Labbé S, Blondin D, Phoenix S, Guérin B, Haman F, Turcotte E, Richard D, Carpentier A. 2012. Brown adipose tissue oxidative metabolism contributes to energy expenditure during acute cold exposure in humans. J Clin Invest 122: $545-552$.

Petrovic N, Walden T, Shabalina I, Timmons J, Cannon B, Nedergaard J. 2010. Chronic peroxisome proliferator-activated receptor $\gamma(\operatorname{PPAR} \gamma)$ activation of epididymally derived white adipocyte cultures reveals a population of thermogenically competent, UCP1-containing adipocytes molecularly distinct from classic brown adipocytes. I Biol Chem 285: 7153-7164.

Pilon AM, Ajay SS, Kumar SA, Steiner LA, Cherukuri PF, Wincovitch S, Anderson SM, Center NCS, Mullikin JC, Gallagher PG, et al. 2011. Genome-wide ChIP-seq reveals a dramatic shift in the binding of the transcription factor erythroid Kruppel-like factor during erythrocyte differentiation. Blood 118: e139-e148.

Pisani D, Djedaini M, Beranger G, Elabd C, Scheideler M, Ailhaud G, Amri E-Z. 2011. Differentiation of human adipose-derived stem cells into 'brite' (brown-in-white) adipocytes. Front Endocrinol 2: 87.

Rada-Iglesias A, Bajpai R, Swigut T, Brugmann S, Flynn R, Wysocka J. 2011. A unique chromatin signature uncovers early developmental enhancers in humans. Nature 470: 279-283.

Rajakumari S, Wu J, Ishibashi J, Lim HW, Giang AH, Won KJ, Reed RR, Seale P. 2013. EBF2 determines and maintains brown adipocyte identity. Cell Metab 17: 562-574.

Robinson MD, McCarthy DJ, Smyth GK. 2010. edgeR: a Bioconductor package for differential expression analysis of digital gene expression data. Bioinformatics 26: 139-140.

Rodriguez A-M, Pisani D, Dechesne C, Turc-Carel C, Kurzenne J-Y, Wdziekonski B, Villageois A, Bagnis C, Breittmayer J-P, Groux H, et al. 2005. Transplantation of a multipotent cell population from human adipose tissue induces dystrophin expression in the immunocompetent mdx mouse. J Exp Med 201: $1397-1405$.

Rosell M, Kaforou M, Frontini A, Okolo A, Chan YW, Nikolopoulou E, Millership S, Fenech ME, MacIntyre D, Turner JO, et al. 2014. Brown and white adipose tissues: intrinsic differences in gene expression and response to cold exposure in mice. Am J Physiol Endocrinol Metab 306: E945E964.

Schmidt S, Jørgensen M, Chen Y, Nielsen R, Sandelin A, Mandrup S. 2011. Cross species comparison of $\mathrm{C} / \mathrm{EBP} \alpha$ and
PPAR $\gamma$ profiles in mouse and human adipocytes reveals interdependent retention of binding sites. BMC Genomics 12: 152 .

Seale P, Conroe H, Estall J, Kajimura S, Frontini A, Ishibashi J, Cohen P, Cinti S, Spiegelman B. 2011. Prdm16 determines the thermogenic program of subcutaneous white adipose tissue in mice. J Clin Invest 121: 96-105.

Sears I, MacGinnitie M, Kovacs L, Graves R. 1996. Differentiation-dependent expression of the brown adipocyte uncoupling protein gene: regulation by peroxisome proliferator-activated receptor $\gamma$. Mol Cell Biol 16: 3410-3419.

Seo S, Lomberk G, Mathison A, Buttar N, Podratz J, Calvo E, Iovanna J, Brimijoin S, Windebank A, Urrutia R. 2012. Krüppel-like factor 11 differentially couples to histone acetyltransferase and histone methyltransferase chromatin remodeling pathways to transcriptionally regulate dopamine D2 receptor in neuronal cells. J Biol Chem 287: 12723-12735.

Sharp LZ, Shinoda K, Ohno H, Scheel DW, Tomoda E, Ruiz L, Hu H, Wang L, Pavlova Z, Gilsanz V, et al. 2012. Human BAT possesses molecular signatures that resemble beige/brite cells. PLOS ONE 7: e49452.

Siersbæk R, Nielsen R, John S, Sung M-H, Baek S, Loft A, Hager G, Mandrup S. 2011. Extensive chromatin remodelling and establishment of transcription factor 'hotspots' during early adipogenesis. EMBO J 30: 1459-1472.

Siersbæk M, Loft A, Aagaard M, Nielsen R, Schmidt S, Petrovic N, Nedergaard J, Mandrup S. 2012. Genome-wide profiling of peroxisome proliferator-activated receptor $\gamma$ in primary epididymal, inguinal, and brown adipocytes reveals depot-selective binding correlated with gene expression. Mol Cell Biol 32: 3452-3463.

Siersbaek R, Rabiee A, Nielsen R, Sidoli S, Traynor S, Loft A, Poulsen LL, Rogowska-Wrzesinska A, Jensen ON, Mandrup S. 2014. Transcription factor cooperativity in early adipogenic hotspots and super-enhancers. Cell Reports 7: 14431455.

Soccio R, Tuteja G, Everett L, Li Z, Lazar M, Kaestner K. 2011. Species-specific strategies underlying conserved functions of metabolic transcription factors. Mol Endocrinol 25: 694-706.

Steger D, Grant G, Schupp M, Tomaru T, Lefterova M, Schug J, Manduchi E, Stoeckert C, Lazar M. 2010. Propagation of adipogenic signals through an epigenomic transition state. Genes Dev 24: 1035-1044.

Tan GD, Fielding BA, Currie JM, Humphreys SM, Desage M, Frayn KN, Laville M, Vidal H, Karpe F. 2005. The effects of rosiglitazone on fatty acid and triglyceride metabolism in type 2 diabetes. Diabetologia 48: 83-95.

van Marken Lichtenbelt W, Vanhommerig J, Smulders N, Drossaerts J, Kemerink G, Bouvy N, Schrauwen P, Teule GJ. 2009. Cold-activated brown adipose tissue in healthy men. $N$ Engl J Med 360: 1500-1508.

Ventura A, Meissner A, Dillon C, McManus M, Sharp P, Van Parijs L, Jaenisch R, Jacks T. 2004. Cre-lox-regulated conditional RNA interference from transgenes. Proc Natl Acad Sci 101: 10380-10385.

Virtanen K, Lidell M, Orava J, Heglind M, Westergren R, Niemi T, Taittonen M, Laine J, Savisto N-J, Enerbäck S, et al. 2009. Functional brown adipose tissue in healthy adults. $N$ Engl J Med 360: 1518-1525.

Waki H, Nakamura $M$, Yamauchi T, Wakabayashi K, Yu J, Hirose-Yotsuya L, Take K, Sun W, Iwabu M, Okada-Iwabu M, et al. 2011. Global mapping of cell type-specific open chromatin by FAIRE-seq reveals the regulatory role of the NFI family in adipocyte differentiation. PLoS Genet 7: e1002311.

Whyte WA, Orlando DA, Hnisz D, Abraham BJ, Lin CY, Kagey MH, Rahl PB, Lee TI, Young RA. 2013. Master transcription 
Loft et al.

factors and mediator establish super-enhancers at key cell identity genes. Cell 153: 307-319.

Wilson-Fritch L, Nicoloro S, Chouinard M, Lazar M, Chui P, Leszyk J, Straubhaar J, Czech M, Corvera S. 2004. Mitochondrial remodeling in adipose tissue associated with obesity and treatment with rosiglitazone. J Clin Invest 114: 1281-1289.

Wu Z, Wang S. 2013. Role of Kruppel-like transcription factors in adipogenesis. Dev Biol 373: 235-243.

Wu J, Bostrom P, Sparks LM, Ye L, Choi JH, Giang AH, Khandekar M, Virtanen KA, Nuutila P, Schaart G, et al. 2012. Beige adipocytes are a distinct type of thermogenic fat cell in mouse and human. Cell 150: 366-376.

Yamamoto K-i, Sakaguchi M, Medina R, Niida A, Sakaguchi Y, Miyazaki M, Kataoka K, Huh N-h. 2010. Transcriptional regulation of a brown adipocyte-specific gene, UCP1, by KLF11 and KLF15. Biochem Biophys Res Commun 400: 175-180.

Ye L, Wu J, Cohen P, Kazak L, Khandekar MJ, Jedrychowski MP, Zeng X, Gygi SP, Spiegelman BM. 2013. Fat cells directly sense temperature to activate thermogenesis. Proc Natl Acad Sci 110: 12480-12485.

Yoneshiro T, Aita S, Matsushita M, Kayahara T, Kameya T, Kawai Y, Iwanaga T, Saito M. 2013. Recruited brown adipose tissue as an antiobesity agent in humans. J Clin Invest 123: 3404-3408.

Zaragosi LE, Billon N, Ailhaud G, Dani C. 2007. Nucleofection is a valuable transfection method for transient and stable transgene expression in adipose tissue-derived stem cells. Stem Cells 25: 790-797.

Zhang JS, Moncrieffe MC, Kaczynski J, Ellenrieder V, Prendergast FG, Urrutia R. 2001. A conserved $\alpha$-helical motif mediates the interaction of Sp1-like transcriptional repressors with the corepressor mSin3A. Mol Cell Biol 21: 5041-5049.

Zhang H, Chen Q, Yang M, Zhu B, Cui Y, Xue Y, Gong N, Cui A, Wang M, Shen L, et al. 2013. Mouse KLF11 regulates hepatic lipid metabolism. J Hepatol 58: 763-770. 


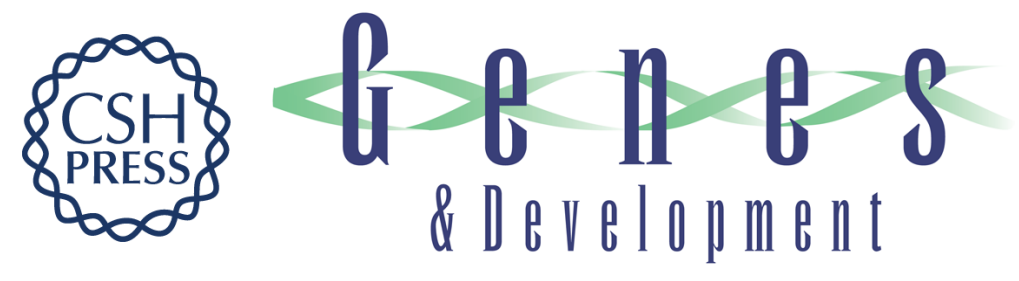

\section{Browning of human adipocytes requires KLF11 and reprogramming of PPAR $\gamma$ superenhancers}

Anne Loft, Isabel Forss, Majken Storm Siersbæk, et al.

Genes Dev. 2015, 29: originally published online December 12, 2014

Access the most recent version at doi:10.1101/gad.250829.114

\section{Supplemental http://genesdev.cshlp.org/content/suppl/2014/12/11/gad.250829.114.DC1 Material}

References This article cites 80 articles, 31 of which can be accessed free at: http://genesdev.cshlp.org/content/29/1/7.full.html\#ref-list-1

Creative This article is distributed exclusively by Cold Spring Harbor Laboratory Press for the first Commons six months after the full-issue publication date (see

License http://genesdev.cshlp.org/site/misc/terms.xhtml). After six months, it is available under a Creative Commons License (Attribution-NonCommercial 4.0 International), as described at http://creativecommons.org/licenses/by-nc/4.0/.

Email Alerting Receive free email alerts when new articles cite this article - sign up in the box at the top Service right corner of the article or click here.

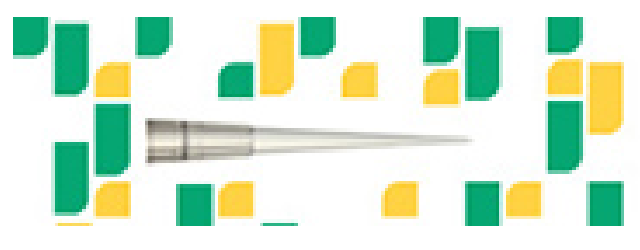

Focused on your science. 